\title{
Response to Noise Emitted by Wind Farms in People Living in Nearby Areas
}

\author{
Małgorzata Pawlaczyk-Łuszczyńska ${ }^{1, *}$, Kamil Zaborowski ${ }^{1}$, Adam Dudarewicz ${ }^{1}$, \\ Małgorzata Zamojska-Daniszewska ${ }^{1}$ and Małgorzata Waszkowska ${ }^{2}$ \\ 1 Department of Physical Hazards, Nofer Institute of Occupational Medicine, 8, Sw. Teresy Str., \\ 91-348 Lodz, Poland; Kamil.Zaborowski@imp.lodz.pl (K.Z.); Adam.Dudarewicz@imp.lodz.pl (A.D.); \\ Malgorzata.Zamojska@imp.lodz.pl (M.Z.-D.) \\ 2 Department of Work Psychology, Nofer Institute of Occupational Medicine, 8, Sw. Teresy Str., \\ 91-348 Lodz, Poland; Malgorzata.Waszkowska@imp.lodz.p1 \\ * Correspondence: Malgorzata.Pawlaczyk@imp.lodz.pl; Tel.: +48-42-63-14-522
}

Received: 13 June 2018; Accepted: 19 July 2018; Published: 25 July 2018

\begin{abstract}
The aim of this study was to evaluate the perception and annoyance of noise from wind turbines in populated areas of Poland. A questionnaire inquiry was carried out among 517 subjects, aged 18-88, living within 204-1726 m from the nearest wind turbine. For areas where respondents lived, A-weighted sound pressure levels (SPLs) were calculated as the sum of the contributions from the wind power plants in the specific area. It has been shown that the wind turbine noise at the calculated A-weighted SPL of 33-50 dB was perceived as annoying or highly annoying by $46 \%$ and $28 \%$ of respondents, respectively. Moreover, $34 \%$ and $18 \%$ of them said that they were annoyed or highly annoyed indoors, respectively. The perception of high annoyance was associated with the A-weighted sound pressure level or the distance from the nearest wind turbine, general attitude to wind farms, noise sensitivity and terrain shape (annoyance outdoors) or road-traffic intensity (annoyance indoors). About $48-66 \%$ of variance in noise annoyance rating might be explained by the aforesaid factors. It was estimated that at the distance of $1000 \mathrm{~m}$ the wind turbine noise might be perceived as highly annoying outdoors by $43 \%$ and $2 \%$ of people with negative and positive attitude towards wind turbines, respectively. There was no significant association between noise level (or distance) and various health and well-being aspects. However, all variables measuring health and well-being aspects, including stress symptoms, were positively associated with annoyance related to wind turbine noise.
\end{abstract}

Keywords: wind turbines; noise; annoyance; health effects

\section{Introduction}

Wind turbines are relatively new sources of community noise and their impact on people's health and well-being has not been completely explained as yet. Nevertheless, it has been shown that subjects living in the vicinity of wind farms are at the risk of being annoyed by the noise-an adverse impact in itself [1-5]. Noise annoyance in turn could lead to sleep disturbances and psychological distress. No direct effects of wind turbine noise on sleep disturbance or psychological stress have been demonstrated, which means that people who do not hear the sound or do not feel disturbed are not adversely affected [5]. However, the latter effects are still disputable.

Annoyance occurs even when the noise levels do not exceed recommended limits, in particular if multiple sources interact and more than one sensory system is stimulated [6]. Generally, people are more likely to be annoyed when A-weighted sound pressure levels exceed $35-40 \mathrm{~dB}$. The proportion of people perceiving wind turbine noise and annoyed by it increases with increasing noise levels [1-3]. 
Earlier results of laboratory tests implied that none of significant psycho-acoustic parameters explained the observed differentiation in subjective reception of the wind turbine noise annoyance [7]. Instead, the results of subsequent studies [8] demonstrated that analyses of the wind turbine noise annoyance should involve the amplitude of modulation, apart from the sound level. However, it is not certain as yet whether or not at a long distance from wind turbines there is also an amplitude modulation which increases the noise annoyance.

Subjective factors such as having turbines visible from the dwelling, negative opinion about wind turbines in general and/or their visual impact on landscape and self-reported sensitivity to noise increase the probability of being annoyed by the wind turbine noise [1,2], while economic benefits obtained from wind turbines reduce the risk of annoyance [3]. It has been also found that terrain characteristics and urbanization affect the perceived annoyance from the wind turbine noise. In particular, people living in the areas with other background noises are less affected than those from quiet areas [2,5].

It is not quite clear, however, how these factors affect each other and whether or not there is a cause-and-effect relation between them. Furthermore, some feedback may occur between them [9]. Meanwhile the laboratory tests conducted by Maffei et al. [10], using the Immersive Virtual Reality technique, imply that the distance from wind turbines is a factor which affects most the subjective evaluation of noise effects. Along with increasing distance, the perceived sound level, annoyance and stress induced by noise are decreased [10].

On the other hand, according to more recently published findings from Health Canada's Community Noise and Health Study (CNHS), there is no association between the exposure to the wind turbine noise and the self-reported or objectively measured health endpoints. However, this study results support an association between the increasing wind turbine noise level and an increase in the prevalence of annoyance in relation to various wind turbine features, including noise, perceived indoor vibration during turbines' operation, visual impacts, shadow flicker, and the aircraft warning lights on top of the turbines [11-14].

Although wind power has been harnessed as a source of electricity for several decades around the world, its dynamic development in Poland is relatively recent. It is no wonder that the data on reactions to the wind turbine noise in populated areas in Poland are rather sparse.

Recently, Mroczek et al. [15] analyzed the impact of the distance between the place of residence and wind farms on the quality of life in nearby areas, but they did not take into consideration the noise produced by the operation of wind turbines. Their study comprising 1277 people living in rural areas up to $2 \mathrm{~km}$ from wind farms showed that a close proximity of wind farms did not result in the deterioration of the quality of life (assessed using the SF-36 General Health Questionnaire). However, the general score of the SF-36 questionnaire obtained by the wind farm area residents was lower than the score achieved by the control group (consisting of 1169 Polish citizens). The most significant differences were observed in domains evaluating general health, physical functioning and mental health $[15,16]$.

The overall aim of this study, which is a continuation of a previous pilot study [17], was to evaluate the perception and annoyance of noise from wind turbines in populated areas in Poland. In particular, the study attempted to:

- Analyze the relationships between the percentage of people being annoyed by the wind turbine noise and noise levels outside their dwellings or the distance from the nearest wind turbine,

- Explore objective (or situational) factors and subjective (or individual) factors affecting the perceived annoyance.

\section{Material and Methods}

A cross-sectional study on the response to the wind turbine noise was carried out, involving people living in the vicinity of ten wind farms located in the northern, central and south-eastern parts 
of Poland in 2011-2014 (Table 1). Nine areas totaling $223.1 \mathrm{~km}^{2}$ were investigated. A questionnaire was applied as the main research tool.

Table 1. Characteristics of investigated areas.

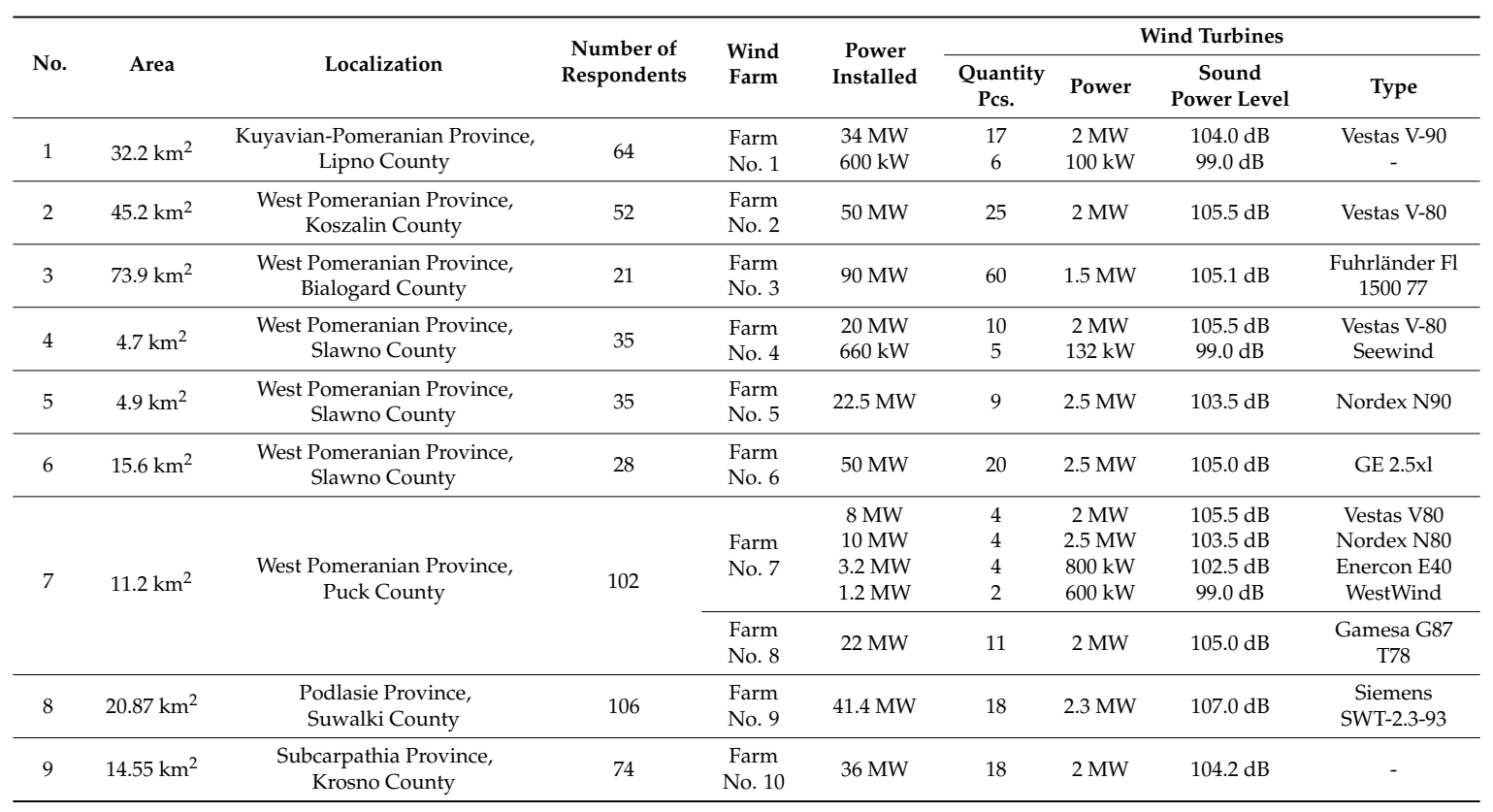

The entire study population comprised 545 subjects aged from 13 to 88 years. They were personally asked to complete questionnaires. Each subject who agreed to participate could be potentially included in the study. However, young people (aged $<18$ years) and those living at a distance above $2 \mathrm{~km}$ as well as very close $(<200 \mathrm{~m})$ to "small" wind turbines were excluded. Thus, the final study group comprised 517 persons, aged 18-88 years, living at a distance of less than $2 \mathrm{~km}$ from the nearest wind turbine. For investigated areas, A-weighted sound pressure levels were calculated as the sum of the contributions from the wind power plants in the neighborhood. In addition, for a number of cases the noise conditions outside the dwellings were at random verified by in situ measurements.

\subsection{Questionnaire Survey}

Subjects were personally asked to fill in an anonymous questionnaire developed to enable evaluation of their living conditions, including the prevalence of annoyance due to noise from wind turbines, and the self-assessment of physical health and well-being. To each household at least one copy of the questionnaire was delivered. The response rate was approximately $78 \%$. Almost all subjects (98\%) completed the questionnaire themselves, except for some elderly people who were interviewed.

The questionnaire was based on the one previously used in Swedish studies [1,2] and, like the aforesaid questionnaire, it was constructed so as to mask the main intention. The responses to most questions were rated on 5-point verbal rating scales.

The questionnaire consisted of two parts. The first part comprised inquiries about the housing and satisfaction with the living environment, including questions on: (a) occurrence and degree of annoyance experienced outdoors and indoors from various nuisances, including the wind turbine noise, (b) paying attention (being sensitive) to noise, odors and air pollution, landscape littering, (c) general opinion on (attitude towards) the wind turbine and on the visual impact of wind turbines, and (d) different visual and auditory aspects of wind turbines, such as noise, shadows and reflections from rotor blades, during various subjects' activities (e.g., relaxing, taking walks) and weather conditions.

The second part of the questionnaire was aimed at self-assessment of subjects' physical health, including their hearing status. It also comprised questions on chronic illnesses (e.g., cardiovascular 
diseases, hearing impairment, etc.) and general well-being (headache, undue tiredness, pain and stiffness in the back, neck, and shoulders, feeling stressed, irritable), as well as the quality of sleep and normal sleep habits. Statistical analysis of data from the pilot study [17] confirmed a high consistency of questions assessing the response to wind turbines by Cronbach's $\alpha$ coefficient equal to 0.936 .

In addition, the current mental health status of a part (79.5\%) of the respondents was assessed using the 12-item Goldberg General Health Questionnaire (GHQ-12) which was adapted for Polish conditions $[18,19]$. This questionnaire was derived from the main version of the Goldberg General Health Questionnaire. It consists of 12 items describing various symptoms of mental health problems related to two areas, i.e., inability to carry out one's normal "healthy" functions and appearance of new phenomena of a distressing nature. The subjects are asked to assess the changes in their mood, feelings and behaviors during the recent four weeks using the 4-point response scale ("less than usual", "no more than usual", "rather more than usual" and "much more than usual").

Two methods are used to score the results of GHQ-12. First, responses to each question were coded on the scale from 0 to 3 . The total score per subject was obtained by adding the scores for 12 questions. The more mental disorders reported (number and severity of symptoms), the higher the total score of the GHQ-12. In addition, to identify the so-called "cases" (i.e., persons with mental health disorders) the GHQ method was applied for the classification. The answers: "less than usual" and "no more than usual" were coded "0" (lack of symptoms), and the answers "rather more than usual", "much more than usual" were coded " 1 " (occurrence of symptoms). In the latter method, the cut-off point between the "non-case" and the "case" for the total score of the questionnaire is $2 / 3$. So, persons with scores 2 or less were classified as "non-cases" (healthy) while persons with scores 3 or more were classified as "cases" [18,19].

\subsection{Noise Exposure Evaluation}

For the areas where the respondents lived, A-weighted sound pressure levels (SPLs) were calculated as the sum of the contributions from the wind turbines in the neighborhood based on the sound propagation model described in ISO 9613-2:1996 [20].

In these calculations, the A-weighted sound power levels of wind turbines specified by manufacturers were used. The arrangements of turbines within each of the farms were obtained from the internet maps (www.geoportal.gov.pl) [21], while the distances between dwellings and turbines were calculated from the GPS data collected in front of the residential premises. Additionally, a correction for the wind velocity distribution was added to the predicted A-weighted SPLs to obtain the day-evening-night noise levels $\left(\mathrm{L}_{\mathrm{den}}\right)$ according to 2002/49/EC [22,23].

The calculated SPLs were at random verified by in situ measurements. Relatively quiet areas without too many masking noises (e.g., noises from agricultural machines, hand held and stationary power tools or road-traffic noise) were chosen. Consequently, for a part $(38 \%)$ of the respondents ( $n=196)$, noise levels were measured outside their dwellings at the height of 1.5 and/or $4 \mathrm{~m}$, at the distance of $3 \mathrm{~m}$ (or more) from the façade. Measuring points were located next to the respondents' houses in such a way that the distance from the nearest turbine was shorter than the distance between the turbine and the respondent's house.

These measurements were carried out according to Polish recommendations on the assessment of environmental noise [24]. However, apart from an equivalent-continuous A-weighted SPL ( $\left.\mathrm{L}_{\text {Aeq, }} \mathrm{T}\right)$, other basic noise parameters, such as $\mathrm{C}$ - and G-weighted sound pressure levels $\left(\mathrm{L}_{\mathrm{Ceq}, \mathrm{T}}\right.$ and $\mathrm{L}_{\mathrm{Geq}, \mathrm{T}}$ ) were measured. In addition, the frequency analysis in 1/3-octave bands from $1.6 \mathrm{~Hz}$ to $20 \mathrm{kHz}$ was performed.

Noise measurements were carried out using a type SVAN 958 sound analyzer (SVANTEK, Warsaw, Poland) with a SVANTEK type SV12L preamplifier and a type SV22L microphone equipped with an outdoor kit type SA 277). At each measuring point, at least five noise samples were collected, lasting in total from 5 to $30 \mathrm{~min}$. Particular attention was paid to avoid masking of noises, such as road-traffic noise, dogs barking, etc. However, it was impossible to exclude birds chirping and insects humming. 
Measurements were carried out during the daytime, with all or most $(>75 \%)$ of the turbines installed on the farms working. According to Polish recommendations, the meteorological parameters (i.e., air temperature, air humidity, barometric pressure, wind velocity and direction) were simultaneously monitored at the height of $3.5 \mathrm{~m}$ using a weather station (Davis Vantage Vue type 6250, Davis Instruments Corporation, Hayward, CA, USA).

\subsection{Data Analysis}

In the present study, the response to the wind turbine noise was analyzed according to answers to inquiries on: (a) occurrence ("yes" or "no") and the degree of annoyance experienced outdoors and indoors from this type of noise ("not at all annoying" $=0$, "a little annoying" $=1$, "rather annoying" $=2$, "annoying" $=3$, or "extremely annoying" $=4$ ); (b) sensitivity to noise and landscape littering ("definitely no" $=0$, "no" $=1$, "no opinion" = 2, "yes" = 3, or "definitely yes" =4); (c) general opinion on (attitude towards) wind turbines and on the visual impact of wind turbines ("very positive" $=0$, "positive" $=1$, "no opinion" $=2$, "negative" $=3$,"very negative" $=4$ ), and (d) different auditory aspects of wind turbines during various subjects' activities (e.g., relaxing, taking walks). The self-assessment of physical health and hearing status ("very poor" $=0$, "poor" $=1$, "rather poor" $=2$, "rather good" $=3$, "good" $=4$, or "very good" =5) and prevalence of various aspects of health and well-being ("never" / almost never" $=0$, "several times a year" $=1$, "several times a month" $=2$, "several times a week" $=3$, "everyday/almost every day" $=4$ ) was also analyzed.

When relevant, the data from 5-point (or 6-point) verbal rating scales were dichotomized. In particular, the annoyance scores $\geq 2$ (answers: "rather annoying", "annoying" and "extremely annoying") were categorized as "annoying", while annoyance scores $\geq 3$ (answers "annoying" or "extremely annoying") as "highly annoying". On the other hand, the other answers (e.g., "not at all annoying" and "a little annoying") were categorized as "not annoying" or "not highly annoying". Similarly, "very poor", "poor" or "rather poor" self-assessment of physical health or hearing status (scores < 3) were categorized as "negative" while the other (i.e., "rather positive", "positive" or "very positive") as positive.

The occurrence of health and well-being aspects (e.g., suffering from headache) at least "a few times per month" (score $\geq 2$ ) was categorized as "frequent", while when analyzing the annoyance due to the wind turbine the same description was used in case of answers: "a few times a week" or "everyday" /"almost every day". Similarly, "very negative" and "negative" attitudes towards the wind turbines (in general and to their visual impact in particular) were categorized as "negative" while the other answers (i.e., "no opinion", "positive" or "very positive") as "positive (not negative)". On the other hand, when analyzing the attention paid to various environmental nuisances, respondents who answered "definitely yes" and "yes" were classified as "sensitive" to noise, landscape littering or air pollution while the others as "not sensitive".

To analyze the relationships between the distance from the nearest wind turbine and/or levels of wind turbine noise at the dwelling and the percentage of people being annoyed (or highly annoyed) by the noise, the study subjects were classified into subgroups (categories) according to the calculated A-weighted SPL at their dwellings (three noise categories, i.e., up to $40 \mathrm{~dB}, 40-45 \mathrm{~dB}$ and above $45 \mathrm{~dB}$ ), as well as according to the distance of their dwellings from the nearest wind turbine (three distance categories, i.e., below $400 \mathrm{~m}, 400-800 \mathrm{~m}$, and above $800 \mathrm{~m}$ ).

Answers to the questionnaire were presented as the proportions with $95 \%$ confidence intervals in the total study group as well as the proportion of respondents in various subgroups. Differences between various pairs of subgroups in proportions of answers were evaluated using the chi-square test.

Relationships between subjective variables and objective variables (i.e., noise and distance categories and noise annoyance rating, noise sensitivity, general attitude to the wind turbine expressed on verbal rating scales, etc.) were analyzed using Spearman's nonparametric rank correlation 
coefficient $r_{\mathrm{s}}$. On the other hand, the association between measured and calculated A-weighted sound pressure levels was assessed using Pearson's correlation coefficient $r$.

Binary logistic regression was used to study the influence of various objective and individual/subjective factors (e.g., noise level and attitude to the wind turbine) on annoyance related to the wind turbine noise. The same tool was applied to determine the relationships between the percentage of respondents annoyed by the wind turbine noise and various factors, including the calculated A-weighted sound pressure level or distance from the nearest wind turbine. The Nagelkerke pseudo- $R^{2}$ was applied as a measure of explained variance while the correct classification rate (CCR) was considered as a measure of fit of logistic model [25].

The statistical analysis was carried out with an assumed level of significance $\alpha=0.05$. However, when comparing pairs of various subgroups of respondents or analyzing several relationships at the same time, to avoid the risk of mass significance, $p$-value divided by number $(N)$ of possible comparisons or correlations $(p=0.05 / \mathrm{N})$ was set as the limit for statistical significance. The statistical analysis employed STATISTICA (version 9.1. StatSoft, Inc.: Tulsa, OK, USA) software package.

\section{Results}

\subsection{Study Population}

The majority of respondents $(84.8 \%)$ lived in privately owned detached or semi-detached houses in the countryside or in small villages, in rural or suburban areas with diversified terrain shape and road-traffic intensity. Almost all respondents (93.4\%) could see one or more wind turbines from their dwelling, backyard or garden. Only a few (6.1\%) of them had profits from the wind turbines (Table 2).

The mean age in the study population was $46.7 \pm 15.8$ years. There were more women than men $(58.2 \%$ vs. $41.8 \%, p<0.05)$. Over half $(53.8 \%)$ of the respondents were employed, whereas $23.4 \%$ of them were pensioners. The majority of subjects had primary $(26.3 \%)$, vocational $(21.8 \%)$ or secondary (high school) education (38.5\%).

Over half of the subjects were classified as sensitive to noise (68.3\%) and landscape littering $(63.6 \%)$. Of the respondents, $40.3 \%$ and $32.3 \%$ declared a negative ("very negative" or "negative") attitude towards wind turbines in general and their visual impact in particular, respectively. Nearly one-third (23.0\%) of the subjects assessed their physical health (as "poor" or "very poor") negatively. Respondents examined using the GHQ-12 obtained the mean score at the level of $12.5 \pm 6.1$. Furthermore, $35.0 \%$ of them were classified as cases according to the GHQ-12 result.

In the majority of cases, there were no significant differences between various noise and distance categories. However, the percentage of subjects negatively assessing wind turbines in general and their impact on landscape in particular, decreased significantly when moving from noise category $>45 \mathrm{~dB}$ (or 40-45 dB) to $<35 \mathrm{~dB}(p<0.0167)$. On the other hand, the greater the distance from the nearest wind turbine, the smaller the percentage of subjects with negative opinion on wind turbines (Table 2).

It is worth emphasizing that a majority of subjective (individual) factors (i.e., sensitivity to various environmental nuisances, attitude to wind turbines, physical and mental health status) were correlated to each other (Table 3). In particular, there was a relatively high positive correlation between the attitude to wind turbines in general and attitude to their visual impact in particular (Spearman's rank correlation coefficient $r_{\mathrm{s}}=0.757, p<0.0001398$ ) as well as between respondents' sensitivity to noise and sensitivity to landscape littering $\left(r_{\mathrm{s}}=0.674, p<0.00013989\right)$. 
Table 2. Study group characteristics.

\begin{tabular}{|c|c|c|c|c|c|c|c|}
\hline \multirow{3}{*}{ Characteristic } & \multicolumn{7}{|c|}{ Respondents } \\
\hline & \multirow{2}{*}{ Total } & \multicolumn{3}{|c|}{ Noise Category } & \multicolumn{3}{|c|}{ Distance Category } \\
\hline & & $\leq 40 \mathrm{~dB}$ & $40-45 \mathrm{~dB}$ & $>45 \mathrm{~dB}$ & $\leq 400 \mathrm{~m}$ & $400-800 \mathrm{~m}$ & $>800 \mathrm{~m}$ \\
\hline Age (year) $(M \pm S D)$ & $46.7 \pm 15.8$ & $48.5 \pm 15.9$ & $46.5 \pm 15.7$ & $44.4 \pm 15.6$ & $44.2 \pm 15.1$ & $47.3 \pm 15.8$ & $45.8 \pm 15.8$ \\
\hline Range & $18.0-88.4$ & $19.0-88.4$ & $18.2-83.3$ & $18.0-78.7$ & $18.0-78.2$ & $19.4-88.4$ & $18.2-82.4$ \\
\hline Gender: male (\%) & 41.8 & 38.2 & 41.5 & 47.4 & 40.8 & 44.1 & 35.5 \\
\hline \multicolumn{8}{|l|}{ Occupation (\%) } \\
\hline employed & 53.8 & $44.4^{\mathrm{a}}$ & 55.2 & $62.5^{\mathrm{a}}$ & $69.4^{\mathrm{b}}$ & 53.5 & $48.4^{b}$ \\
\hline students & 1.7 & 1.5 & 1.7 & 2.1 & 4.1 & 1.4 & 1.6 \\
\hline pensioners & 23.4 & 27.1 & 22.9 & 19.8 & 16.3 & 24.6 & 23.0 \\
\hline farmers & 15.1 & 11.3 & 15.6 & 18.8 & 24.5 & 15.0 & 11.5 \\
\hline Residence: detached houses/farms (\%) & 84.8 & 84.5 & 82.7 & 91.6 & 83.7 & 86.4 & 80.8 \\
\hline \multicolumn{8}{|l|}{ Sensitive to $(\%)$} \\
\hline noise & 68.3 & 70.3 & 65.2 & 74.5 & $85.4^{\mathrm{a}}$ & $65.3^{\mathrm{a}}$ & 69.7 \\
\hline landscape littering & 63.6 & 66.4 & 60.1 & 70.2 & 77.1 & 63.4 & 58.8 \\
\hline air pollution & 65.9 & $76.2^{\mathrm{a}}$ & $59.7^{\mathrm{a}}$ & 70.2 & $83.3^{\mathrm{a}}$ & $61.9^{\mathrm{a}}$ & 70.0 \\
\hline \multicolumn{8}{|l|}{ Negative (\%) } \\
\hline Attitude to wind turbines in general & 40.3 & $38.3^{\mathrm{a}}$ & $38.6^{\mathrm{b}}$ & $47.3^{\mathrm{a}, \mathrm{b}}$ & $48.9^{\mathrm{a}}$ & $43.2^{\mathrm{b}}$ & $28.0^{a, b}$ \\
\hline Attitude to visual impact of wind turbines & 32.3 & 34.4 & 29.9 & 36.8 & 36.7 & $35.1^{\mathrm{a}}$ & $22.7^{\mathrm{a}}$ \\
\hline Self-assessment of physical health & 23.0 & 22.7 & 22.3 & 25.3 & 28.6 & 23.4 & 19.7 \\
\hline Self-assessment of hearing status & 15.2 & 13.0 & 17.1 & 12.9 & 11.9 & 17.7 & 9.6 \\
\hline Score in the GHQ-12 $(\mathrm{M} \pm \mathrm{SD})$ & $12.5 \pm 6.1$ & $12.3 \pm 5.6$ & $11.5 \pm 4.8$ & $12.0 \pm 7.6$ & $13.3 \pm 8.2$ & $12.7 \pm 6.1$ & $11.5 \pm 4.8$ \\
\hline Range & $1.0-36.0$ & $1.0-31.0$ & $2.0-36.0$ & $2.0-33.0$ & $3.0-33.0$ & $1.0-36.0$ & $5.0-31.0$ \\
\hline \multicolumn{8}{|l|}{ Respondents (\%) } \\
\hline $\begin{array}{l}\text { Classified as cases on the basis of the } \\
\text { GHQ-12 score }\end{array}$ & 35.0 & 32.5 & 37.4 & 32.0 & 31.7 & 38.3 & 28.3 \\
\hline $\begin{array}{l}\text { Who can see at least one wind turbine } \\
\text { from their dwelling }\end{array}$ & 93.4 & 91.0 & 94.1 & 94.8 & 98.0 & 93.9 & 90.2 \\
\hline With profits from wind turbines & 6.1 & $0.0^{\mathrm{a}}$ & $6.6^{b}$ & $12.6^{\mathrm{a}, \mathrm{b}}$ & 6.1 & $7.9^{\mathrm{a}}$ & $0.9^{\mathrm{a}}$ \\
\hline Study group (n) & 517 & 133 & 288 & 96 & 49 & 346 & 122 \\
\hline
\end{tabular}

M-mean; SD—standard deviation; GHQ-12-12-item Goldberg's General Health Questionnaire; $\mathrm{a}, \mathrm{b}$ Significant differences between noise or distance categories $(p<0.01667)$.

Table 3. Relationships between various subjective variables in the study group ${ }^{1}$. Statistically significant correlations are presented in bold numbers $(p<0.0013989)$.

\begin{tabular}{|c|c|c|c|c|c|c|c|c|c|}
\hline & \multicolumn{9}{|c|}{ Spearman's Rank Correlation Coefficient } \\
\hline & 1 & 2 & 3 & 4 & 5 & 6 & 7 & 8 & 9 \\
\hline 1. Age & & -0.470 & 0.050 & -0.032 & 0.012 & 0.106 & 0.093 & -0.413 & 0.096 \\
\hline 2. Education & & & 0.152 & 0.176 & -0.014 & -0.101 & 0.016 & 0.285 & -0.040 \\
\hline 3. Sensitivity to noise & & & & 0.674 & -0.432 & 0.342 & 0.306 & -0.244 & 0.229 \\
\hline 4. Sensitivity to landscape littering & & & & & -0.508 & 0.464 & 0.438 & -0.222 & 0.318 \\
\hline 5. Opinion about wind turbines impact on health & & & & & & -0.756 & -0.661 & 0.422 & -0.345 \\
\hline 6. Attitude to wind turbines in general & & & & & & & 0.757 & -0.424 & 0.467 \\
\hline 7. Attitude to visual impact of wind turbines & & & & & & & & -0.260 & 0.337 \\
\hline 8. Self-assessment of physical health & & & & & & & & & -0.406 \\
\hline 9. Score in the GHQ-12 & & & & & & & & & \\
\hline
\end{tabular}

9. Score in the GHQ-12

${ }^{1}$ Except for age and the GHQ-12 score, the analyzed variables are presented on 5-point or 6-point rating scale. To avoid the risk of mass significance, $p<0.001389$ was required for statistical significance; GHQ-12-12-item Goldberg's General Health Questionnaire.

\subsection{Noise Exposure Evaluation}

The study subjects lived within 204 to $1726 \mathrm{~m}$ from the nearest wind turbine. They were exposed to noise at the equivalent-continuous: (a) A-weighted SPLs of 33-50 dB (mean value (M) \pm standard deviation (SD): $42.6 \pm 3.5 \mathrm{~dB}$, median (Me): $42.6 \mathrm{~dB}$ ); (b) C-weighted SPLs of 46-70 dB (M \pm SD: $57.7 \pm 5.7 \mathrm{~dB}$, Me: $58 \mathrm{~dB}$ ); (c) G-weighted SPLs of 53-90 dB (M \pm SD: $72.4 \pm 8.6 \mathrm{~dB}, \mathrm{Me}: 72.4 \mathrm{~dB})$. The noise at respondents' dwellings included infrasonic components but at levels lower than the relevant hearing threshold levels (Figure 1). 


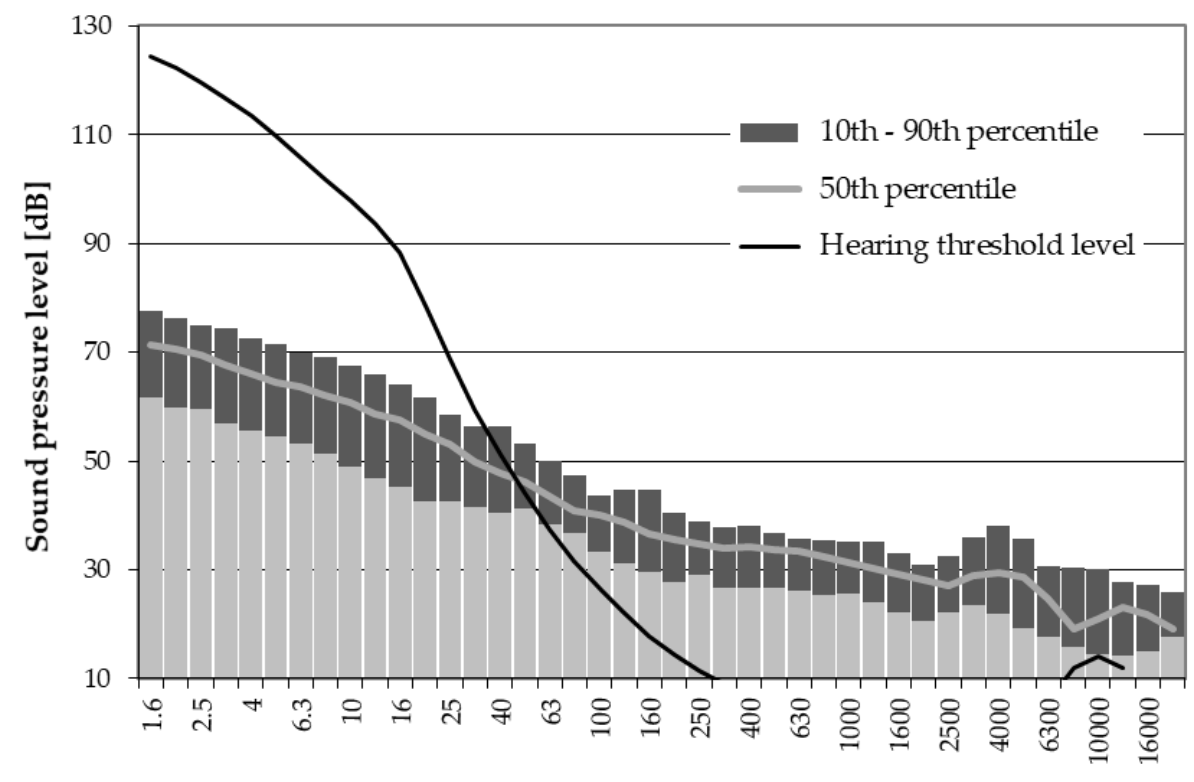

1/3-octave band frequency $[\mathrm{Hz}]$

Figure 1. 1/3-octave band spectra of noise measured outside respondents' dwellings together with the hearing threshold level in the infrasonic and audible frequency range [26,27].

It is worth noting that during noise measurements almost all meteorological parameters, excluding air velocity, fulfilled the requirements of the applied measuring method [24]. In particular, atmospheric pressure remained within the range of $974-1028 \mathrm{hPa}$, relative humidity varied from $25 \%$ to $92 \%$, while air velocity ranged from 0 to $20 \mathrm{~m} / \mathrm{s}$. The latter parameter did not exceed the limit value $(5 \mathrm{~m} / \mathrm{s})$ in $79.5 \%$ of analyzed cases.

In the areas where respondents lived, the calculated A-weighted SPLs ranged from 33.7 to $49.9 \mathrm{~dB}$, while corresponding exposure metrics $\mathrm{L}_{\mathrm{den}}$ varied from 35 to $53 \mathrm{~dB}$ (Table 4 ). It should be noted that the mean value of the difference between calculated and measured A-weighted SPLs outside respondents' dwellings was $0.6 \mathrm{~dB}(95 \% \mathrm{CI}$ : $-6.5-3.9 \mathrm{~dB})$, while Pearson's $r$ correlation coefficient between these noise levels was $0.31(p=0.00002)$.

Over half of the subjects (55.7\%) were exposed to noise at the calculated A-weighted sound pressure levels of $40-45 \mathrm{~dB}$, while over two-thirds (66.9\%) lived at a distance of $400-800 \mathrm{~m}$ from the nearest wind turbine (Table 4). 
Table 4. Summary results of noise calculations for areas where the respondents lived, with a distance of their dwellings from the nearest wind turbine.

\begin{tabular}{|c|c|c|c|c|}
\hline \multirow{3}{*}{ Study Group } & \multirow{3}{*}{$\begin{array}{l}\text { Number of } \\
\text { Subjects }\end{array}$} & $\begin{array}{l}\text { A-Weighted Sound } \\
\text { Pressure Level (dB) }\end{array}$ & $\begin{array}{l}\text { Day-Evening-Night } \\
\text { Noise Level, } \mathrm{L}_{\mathrm{den}}(\mathrm{dB})\end{array}$ & Distance (m) \\
\hline & & \multicolumn{3}{|c|}{$\mathrm{M} \pm \mathrm{SD}(\mathrm{Me})$} \\
\hline & & \multicolumn{3}{|c|}{ Range } \\
\hline Total subjects & 517 & $\begin{array}{c}42.1 \pm 3.1(41.7) \\
33.7-49.9\end{array}$ & $\begin{array}{c}46.8 \pm 3.1(46.4) \\
38.4-54.6\end{array}$ & $\begin{array}{c}665 \pm 194(656) \\
204-1726\end{array}$ \\
\hline \multicolumn{5}{|c|}{ Noise category } \\
\hline$\leq 40 \mathrm{~dB}$ & 133 & $\begin{array}{c}38.1 \pm 1.4(38.1) \\
33.7-40.0\end{array}$ & $\begin{array}{c}42.8 \pm 1.4(42.8) \\
38.4-44.7\end{array}$ & $\begin{array}{c}819 \pm 163(795) \\
353-1726\end{array}$ \\
\hline $40-45 \mathrm{~dB}$ & 288 & $\begin{array}{l}42.4 \pm 1.5(42.1) \\
40.1-46.0\end{array}$ & $\begin{array}{l}47.1 \pm 1.5(46.8) \\
44.8-50.7\end{array}$ & $\begin{array}{c}669 \pm 156(648) \\
235-998\end{array}$ \\
\hline$>45 \mathrm{~dB}$ & 96 & $\begin{array}{c}46.4 \pm 1.5(46.3) \\
43.6-49.9\end{array}$ & $\begin{array}{c}51.1 \pm 1.5(51.0) \\
48.3-54.6\end{array}$ & $\begin{array}{c}440 \pm 97(441) \\
204-617\end{array}$ \\
\hline \multicolumn{5}{|c|}{ Distance category } \\
\hline$\leq 400 \mathrm{~m}$ & 49 & $\begin{array}{c}46.3 \pm 2.4(46.7) \\
39.3-49.9\end{array}$ & $\begin{array}{c}51.0 \pm 2.4(51.4) \\
44.0-54.6\end{array}$ & $\begin{array}{c}344 \pm 51(365) \\
204-92\end{array}$ \\
\hline $400-800 \mathrm{~m}$ & 346 & $\begin{array}{c}42.4 \pm 2.7(42.7) \\
37.0-47.6\end{array}$ & $\begin{array}{c}47.1 \pm 2.7(47.4) \\
41.7-52.3\end{array}$ & $\begin{array}{c}622 \pm 108(618) \\
403-800\end{array}$ \\
\hline$>800$ & 122 & $\begin{array}{c}39.4 \pm 2.2(40.4) \\
33.7-42.0\end{array}$ & $\begin{array}{c}44.1 \pm 2.2(45.1) \\
38.4-46.7\end{array}$ & $\begin{array}{c}915 \pm 125(891) \\
801-1726\end{array}$ \\
\hline
\end{tabular}

$\mathrm{M}-$ mean; SD—standard deviation; $\mathrm{Me}$-median; $\mathrm{CI}-$ confidence interval.

\subsection{Questionnaire Survey}

\subsubsection{Main Results-Assessment of Environmental Conditions}

Generally, over half of the respondents paid attention to environmental nuisances at their dwelling places, such as odors and air pollution $(65.9 \%)$, landscape littering $(63.6 \%)$ and noise from various sources (68.3\%) (see Table 2 for the percentage of the subjects classified as sensitive to the mentioned factors). The most frequently reported nuisances which were noticed outside the dwellings were the wind turbine noise $(65.2 \%)$, road traffic noise $(56.3 \%)$, noise from hand held and stationary power tools $(47.4 \%)$ and noise from agricultural machinery $(47.0 \%)$.

There were significant differences between the proportions of subjects perceiving (both outdoors and indoors) the wind turbine noise and other environmental nuisances, excluding the road-traffic noise (Figure 2). The wind turbine noise was perceived by a higher percentage of respondents. Furthermore, it was significantly more frequently perceived as annoying (or highly annoying) than other environmental nuisances, in particular the road-traffic noise (Table 5).

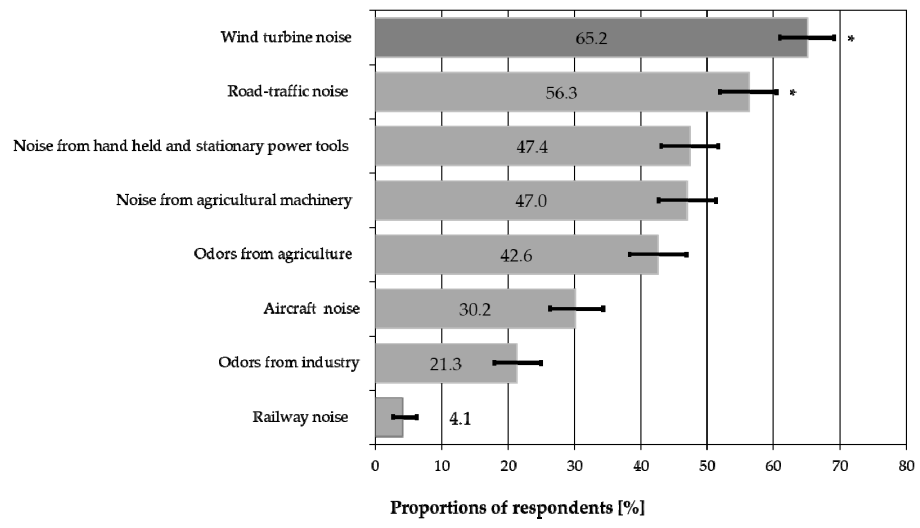

(a)

Figure 2. Cont. 


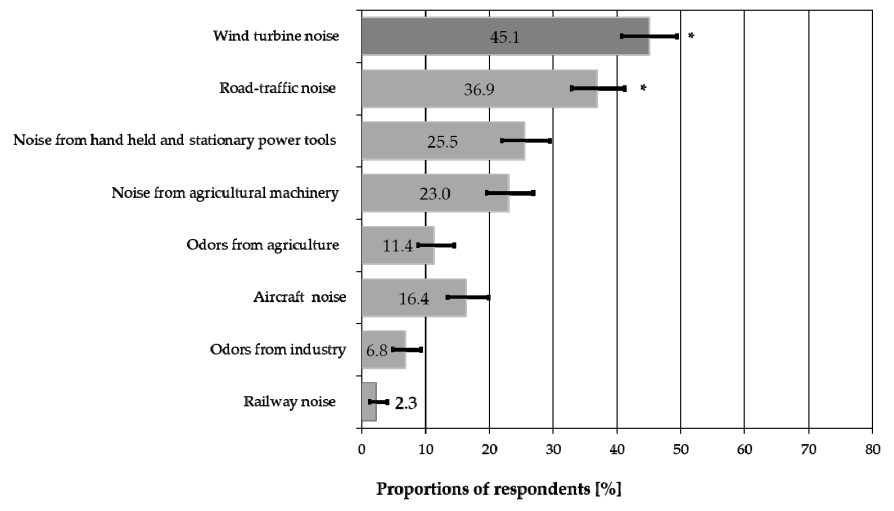

(b)

Figure 2. Comparison of proportions (with 95\% confidence intervals) of respondents who perceived the wind turbine noise and other environmental nuisances (a) outdoors and (b) indoors. Cases without a significant difference are denoted $(*)(p>0.00625)$. For other cases, significant differences were found.

Table 5. Comparison of proportions (with 95\% confidence intervals) of respondents who were annoyed (or highly annoyed) by the wind turbine noise and other environmental nuisances ${ }^{1}$.

\begin{tabular}{|c|c|c|c|c|}
\hline \multirow{4}{*}{ Environmental Nuisances } & \multicolumn{4}{|c|}{ Proportion of Respondents (\%) } \\
\hline & \multicolumn{4}{|c|}{$95 \% \mathrm{CI}$} \\
\hline & \multicolumn{2}{|c|}{ Annoyed } & \multicolumn{2}{|c|}{ Highly Annoyed } \\
\hline & Outdoors & Indoors & Outdoors & Indoors \\
\hline Wind turbine noise & $46.4(42.2-50.7)$ & $33.7(29.7-37.8)$ & $28.0(24.4-32.1)$ & $18.4(15.3-22.0)$ \\
\hline Road-traffic noise & $28.4(24.7-32.5)$ & $18.4(15.3-22.0)$ & $12.0(9.5-15.1)$ & $9.7(7.4-12.6)$ \\
\hline Noise from hand held and stationary power tools & $17.0(14.0-20.5)$ & $10.8(8.4-13.8)$ & $6.6(4.7-9.1)$ & $3.9(2.5-5.9)$ \\
\hline Noise from agricultural machinery & $12.8(10.2-15.9)$ & $7.7(5.7-10.4)$ & $4.3(2.8-6.4)$ & $2.5(1.4-4.3)$ \\
\hline Odors from agriculture & $18.6(15.5-22.2)$ & $6.4(4.6-8.9)$ & $7.4(5.4-10.0)$ & $2.7(1.6-4.6)$ \\
\hline Aircraft noise & $12.8(10.2-15.9)$ & $7.2(5.2-9.7)$ & $3.9(2.5-5.9)$ & $2.9(1.7-4.8)$ \\
\hline Odors from industry & $18.2(15.1-21.8)$ & $7.0(5.1-9.5)$ & $8.9(6.7-11.7)$ & $3.7(2.3-5.7)$ \\
\hline Railway noise & $0.8(0.2-2.1)$ & $1.0(0.4-2.3)$ & $0.6(0.1-1.8)$ & $0.2(0.0-1.2)$ \\
\hline
\end{tabular}

${ }^{1}$ To avoid the risk of mass significance, $p<0.00625$ was required for statistical significance. There were significant differences between proportions of respondents who were annoyed (or highly annoyed) by the wind turbine noise and other environmental nuisances $(p<0.00625) ; \mathrm{CI}-$ confidence interval.

Generally, the wind turbine noise was perceived outdoors by $65.2 \%$ of subjects, while $45.1 \%$ of them perceived it indoors (Table 6).

Moreover, this type of noise was assessed outdoors as annoying (i.e., as "rather annoying", "annoying" or "extremely annoying" using a 5-point verbal scale) or highly annoying (i.e., as "annoying" or "extremely annoying") by $46.4 \%$ and $28.0 \%$ of respondents, respectively. On the other hand, $33.7 \%$ and $18.4 \%$ of subjects said that they were annoyed or highly annoyed indoors, respectively. Results of noise annoyance ratings before dichotomization are presented in Figure 3.

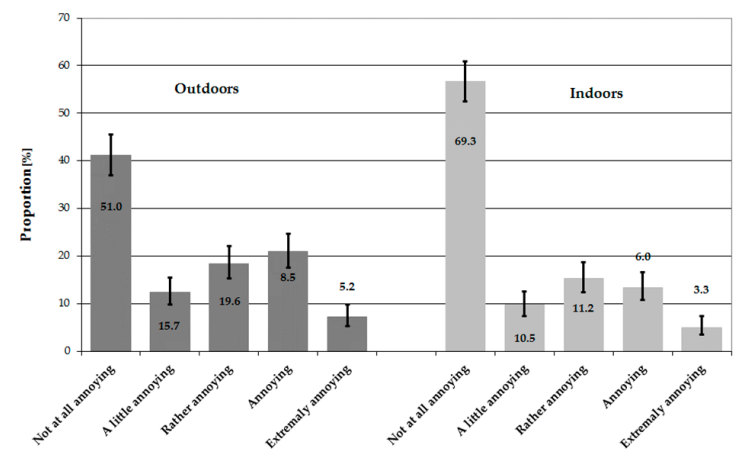

Figure 3. Results of assessment of annoyance due to the wind turbine noise on the 5-point verbal rating scale (outdoors and indoors) in total. Data are presented as proportions with $95 \%$ confidence intervals. 
Table 6. Proportions (with 95\% confidence intervals) of respondents who noticed and were annoyed or highly annoyed by the wind turbine noise in total and in each of the noise and distance categories ${ }^{1}$.

\begin{tabular}{|c|c|c|c|c|c|c|}
\hline \multirow{4}{*}{$\begin{array}{c}\text { Group of } \\
\text { Respondents }\end{array}$} & \multicolumn{6}{|c|}{ Proportion of Respondents (\%) } \\
\hline & \multicolumn{6}{|c|}{$(95 \% \mathrm{Cl})$} \\
\hline & \multicolumn{2}{|c|}{$\begin{array}{l}\text { Perceived Wind Turbine } \\
\text { Noise }\end{array}$} & \multicolumn{2}{|c|}{$\begin{array}{l}\text { Annoyed by Wind } \\
\text { Turbine Noise }\end{array}$} & \multicolumn{2}{|c|}{$\begin{array}{l}\text { Highly Annoyed by Wind } \\
\text { Turbine Noise }\end{array}$} \\
\hline & Outdoors & Indoors & Outdoors & Indoors & Outdoors & Indoors \\
\hline Total & $\begin{array}{c}65.2 \\
(61.0-69.2)\end{array}$ & $\begin{array}{c}45.1 \\
(40.8-49.4)\end{array}$ & $\begin{array}{c}46.4 \\
(42.2-50.7)\end{array}$ & $\begin{array}{c}33.7 \\
(29.7-37.8)\end{array}$ & $\begin{array}{c}28.0 \\
(24.4-32.1)\end{array}$ & $\begin{array}{c}18.4 \\
(15.3-22.0)\end{array}$ \\
\hline \multicolumn{7}{|l|}{ Noise category } \\
\hline$\leq 40 \mathrm{~dB}$ & $\begin{array}{c}67.7 \\
(59.3-75.0) \\
\end{array}$ & $\begin{array}{c}42.9 \\
(34.8-51.4) \\
\end{array}$ & $\begin{array}{c}47.4 \\
(39.1-55.8) \\
\end{array}$ & $\begin{array}{c}28.6 \\
(21.6-36.8) \\
\end{array}$ & $\begin{array}{c}24.1 \\
(17.6-32.1) \\
\end{array}$ & $\begin{array}{c}14.3 \\
(9.3-21.4) \\
\end{array}$ \\
\hline $40-45 \mathrm{~dB}$ & $\begin{array}{c}63.2 \\
(57.5-68.6)\end{array}$ & $\begin{array}{c}44.1 \\
(38.5-49.9)\end{array}$ & $\begin{array}{c}44.4 \\
(38.8-50.2)\end{array}$ & $\begin{array}{c}33.3 \\
(28.1-39.0)\end{array}$ & $\begin{array}{c}27.1 \\
(22.3-32.5)\end{array}$ & $\begin{array}{c}18.8 \\
(14.7-23.7)\end{array}$ \\
\hline$>45 \mathrm{~dB}$ & $\begin{array}{c}67.7 \\
(57.8-76.2)\end{array}$ & $\begin{array}{c}51.0 \\
(41.2-60.8)\end{array}$ & $\begin{array}{c}51.0 \\
(41.2-60.8)\end{array}$ & $\begin{array}{c}41.7 \\
(32.3-51.7)\end{array}$ & $\begin{array}{c}36.5 \\
(27.5-46.5)\end{array}$ & $\begin{array}{c}22.9 \\
(15.6-32.4)\end{array}$ \\
\hline \multicolumn{7}{|l|}{ Distance category } \\
\hline$\leq 400 \mathrm{~m}$ & $\begin{array}{c}77.6 \\
(63.9-87.1)\end{array}$ & $\begin{array}{c}59.2 \\
(45.2-71.8)\end{array}$ & $\begin{array}{c}53.1 \\
(39.4-66.3)^{\mathrm{a}}\end{array}$ & $\begin{array}{c}44.9 \\
(31.9-58.7)^{\text {a }}\end{array}$ & $\begin{array}{c}36.7 \\
(24.7-50.8)^{\mathrm{a}}\end{array}$ & $\begin{array}{c}24.5 \\
(14.5-38.3)^{\mathrm{a}}\end{array}$ \\
\hline $400-800 \mathrm{~m}$ & $\begin{array}{c}66.8 \\
(61.6-71.5)\end{array}$ & $\begin{array}{c}50.3 \\
(45.0-55.5)\end{array}$ & $\begin{array}{c}50.3 \\
(45.0-55.5)\end{array}$ & $\begin{array}{c}37.9 \\
(32.9-43.1)^{\mathrm{b}}\end{array}$ & $\begin{array}{c}30.6 \\
(26.0-35.7)^{\mathrm{b}}\end{array}$ & $\begin{array}{c}21.1 \\
(17.1-25.7)^{b}\end{array}$ \\
\hline$>800 \mathrm{~m}$ & $\begin{array}{c}55.7 \\
(46.9-64.2)\end{array}$ & $\begin{array}{c}24.6 \\
(17.8-33.0)\end{array}$ & $\begin{array}{c}32.8 \\
(25.1-41.6)^{\mathrm{a}}\end{array}$ & $\begin{array}{c}17.2 \\
(11.5-25.0)^{a, b}\end{array}$ & $\begin{array}{c}17.2 \\
(11.5-25.0) \mathrm{a}, \mathrm{b}\end{array}$ & $\begin{array}{c}8.2 \\
(4.4-14.6)^{a, b}\end{array}$ \\
\hline
\end{tabular}

${ }^{1}$ Individual noise and distance categories were compared in pairs. To avoid the risk of mass significance, $p<0.0167$ was required for statistical significance; ${ }^{\mathrm{a}, \mathrm{b}}$ Significant differences between distance categories $(p<0.0167)$; CI-confidence interval.

The proportion of subjects being annoyed (or highly annoyed), both outdoors and indoors, in majority cases decreased significantly with a longer distance. Similar relationships were observed when analyzing the proportions of respondents who perceived the wind turbine noise (both outdoors and indoors) (Table 6 and Figure 4). However, the differences between various distance categories were not significant $(p>0.0167)$.

On the other hand, when analyzing the perception and annoyance of the wind turbine noise (both outdoors and indoors) in various noise categories, no significant differences were noted. The only tendency found was the tendency to increase the percentage of subjects being highly annoyed outdoors or annoyed (and highly annoyed) indoors along with increasing noise levels (Table 6 and Figure 4).

The wind turbine noise was most frequently reported when relaxing outdoors $(55.2 \%, 95 \%$ CI: $50.9-59.5 \%)$, taking walks (50.9\%, 95\% CI: 46.5-55.3\%) and during quiet outdoor activities (50.5\%, 95\% CI: 46.1-54.9\%) and get-together outdoors such as barbecue (49.6\%, 95\% CI: $45.2-54.0 \%)$. Respondents were also most often annoyed (37.3-40.4\%) and highly annoyed (22.8-26.7\%) during the mentioned activities.

The percentage of respondents who perceived the wind turbine noise and assessed it as annoying (or highly annoying) during various indoor and outdoor activities decreased significantly along with a longer distance. In particular, the proportions of subjects highly annoyed while relaxing outdoors, taking walks and get-together outdoors decreased significantly from $30.6-34.7 \%$ to $11.5-13.1 \%$ at a distance below $400 \mathrm{~m}$ and above $800 \mathrm{~m}(p<0.0167)$, respectively. However, there were no significant differences between noise categories.

It is worth emphasizing that both in case of general questions on evaluation of living conditions and more specific questions concerning wind turbines, the relationships between the distance (or noise) and "high annoyance" were more pronounced than in the case of "annoyance". 


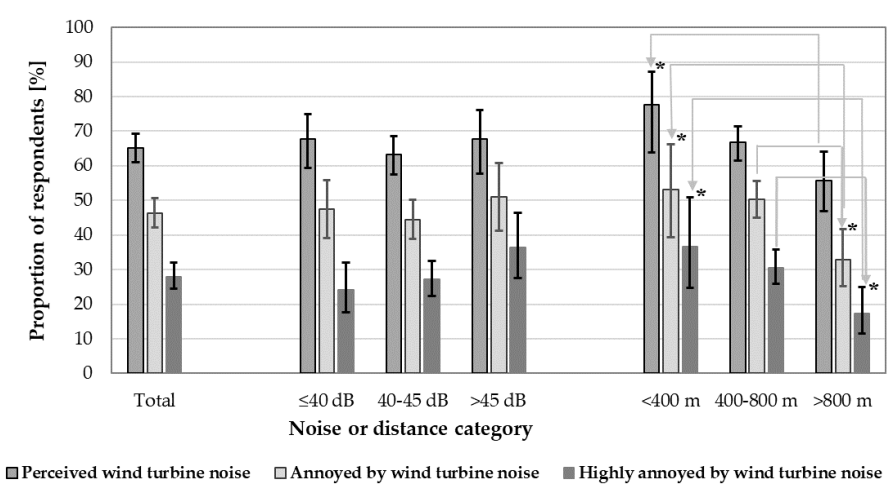

(a)

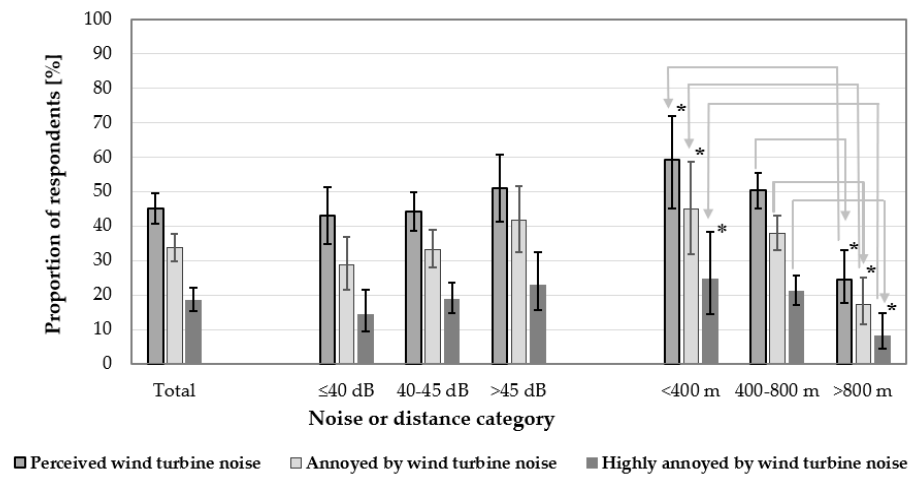

(b)

Figure 4. Comparison of proportions (with 95\% confidence intervals) of respondents who perceived and were annoyed or highly annoyed by the turbine noise (a) outdoors and (b) indoors in total and in each of the noise and distance categories. Significant differences between distance categories are marked $\left.{ }^{*}\right)(p<0.0167)$.

Generally, 40.0\% (95\% CI: 35.9-44.3\%) of the respondents were frequently ("almost every day" or "at least once a week") disturbed by the wind turbine noise. Proportions of those frequently disturbed by the noise decreased significantly from $44.2 \%$ (95\% CI: 3.1-49.5\%) at a distance of $400-800 \mathrm{~m}$ to 26.2\% (95\% CI: 19.2-34.7\%) at a distance above $800 \mathrm{~m}(p<0.0167)$, whereas there were no significant differences between various noise categories. Furthermore, outdoors the subjects were most often annoyed by the wind turbine noise in the evening (25.2\%, 95\% CI: 19.8-31.6\%), while indoors-in the evening (16.2\%, 95\% CI: 11.8-21.8\%) and at night (16.2\%, 95\% CI: 11.8-21.8\%) (Figure 5).

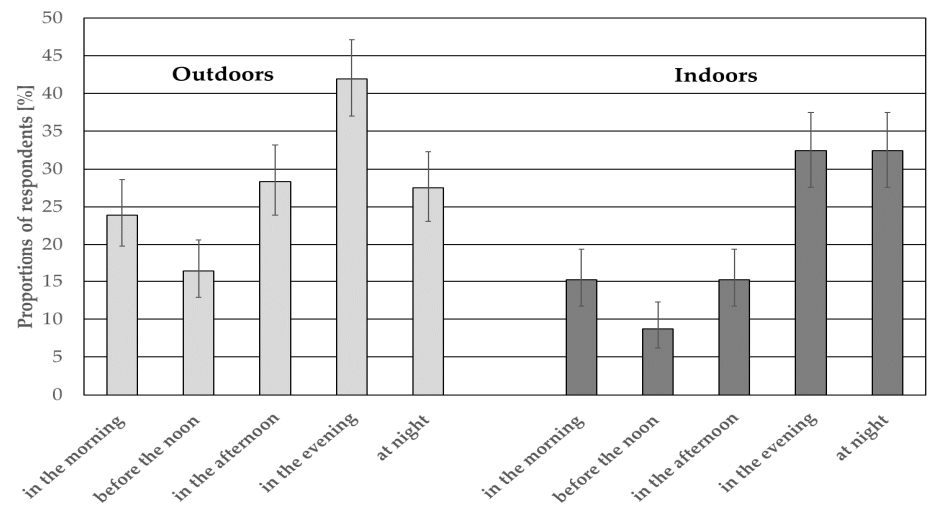

Figure 5. Proportions (with 95\% confidence intervals) of respondents being annoyed by the wind turbine noise at different times of the day. 
About two-thirds of the respondents (64.8\%, 95\% CI: 60.6-68.8\%) indicated rotor blades as the main source of the wind turbine noise, while the noise from the turbine machinery was reported only by $22.1 \%$ (95\% CI: $18.7-25.8 \%$ ) of them. Similarly, in all noise and distance categories, higher proportions of respondents perceived noise from the rotor blades than from the machinery. However, the percentage of subjects indicating the rotor blades as the main source of noise was decreased with a higher distance from the nearest wind turbine, while the machinery was more often pointed by respondents living in areas with higher noise levels. Furthermore, a higher percentage of respondents were perceiving noise from the rotor blade, as compared to machinery ( $50.7 \%, 95 \%$ CI: $46.4-55.0 \%$ vs. $19.3 \%, 95 \%$ CI: $16.2-23.0 \%, p<0.05)$ and they often (at least "a few times a week") found it disturbing $(35.85,95 \% \mathrm{CI}$ : $31.8-40.0 \%$ vs. $15.7 \%, 95 \%$ CI: $12.8-19.1 \%, p<0.05)$.

The most frequent verbal descriptors of the wind turbine noise characteristics were "humming" (52.4\%, 95\% CI: 48.0-56.7\%), "very quiet" (19.8\%, 95\% CI: 16.6-23.6\%) and "whistling" (17.5\%, 95\% CI: $14.4-21.0 \%)$. Weather conditions had an impact on the noise perception. Of total respondents, $46.6 \%$ (95\% CI: 42.4-50.9\%) reported that they could hear the noise more clearly than usual when the wind was blowing from the turbine towards their dwelling, while only $8.9 \%$ (95\% CI: $6.7-11.7 \%)$-when the wind was blowing from the opposite direction. The noise was more clearly heard when a rather strong wind was blowing (51.1\%. 95\% CI: $46.8-55.3 \%)$ and during warm summer nights $(28.6 \%$, $95 \%$ CI: $24.9-32.7 \%)$.

When asked for a general assessment of wind turbines, the respondents most frequently characterized them as "necessary" (38.9\%, 95\% CI: 34.8-43.2\%) and "annoying" (34.2\%, 95\% CI: $30.3-38.4 \%$ ). Furthermore, subjects living at a distance $<400 \mathrm{~m}$ from the nearest wind turbine more often than those living at a distance $>800 \mathrm{~m}$ described them as "annoying" $(42.9 \%, 95 \%$ CI: $30.1-56.7 \%$, vs. $23.0 \%, 95 \%$ CI: $16.4-31.2 \%, p<0.0167)$. On the other hand, respondents exposed to a lower sound pressure level (noise category below $40 \mathrm{~dB}$ ) less frequently than those exposed to a higher noise level (above $45 \mathrm{~dB}$ ) characterized wind turbines as "necessary" (31.6\%, 95\% CI: 24.3-39.9\%, vs. 50.0\%, 95\% CI: $40.2-59.8 \%, p<0.0167)$.

\subsubsection{Self-Assessment of Physical Health and Well-Being}

Over one-fifth of the respondents $(23.0 \%)$ assessed their physical health as "poor" or "very poor" while nearly every fifth or fourth subject frequently (i.e., at least "a few times per month") reported headache $(21.3 \%)$, undue tiredness $(27.1 \%)$, feeling nervous, tense or stressed $(28.0 \%)$, with pain and stiffness in the back, neck or shoulder (24.2\%). Furthermore, of total respondents, $25.1 \%$ often had difficulty falling asleep, $19.3 \%$ of them complained of insomnia. About half (54.2\%) of them often woke up well-rested (badly rested) (Table 7).

Regarding sleep disturbances, $27.3 \%$ of the subjects admitted they were disturbed in their sleep by noise from various sources (including the road traffic noise and the wind turbine noise) when sleeping with the window open, while $15.1 \%$ of them were thus disturbed when sleeping with closed windows. Moreover, about one-third (33.7\%) of the study subjects stated that they were wakened by wind turbines.

Respondents examined using the GHQ-12 obtained the mean score at the level of $12.5 \pm 6.1$ which was close to the normative result for the reference Polish population $(11.17 \pm 5.11)[18,19]$. Furthermore, the prevalence of "cases" (35\%) in the study population was comparable to that observed in the healthy working Polish population (27\%) [18].

As to various health and well-being aspects, there were no significant differences between noise or distance categories (Figure 6). However, the people being annoyed or highly annoyed by the wind turbine noise more frequently than those not annoyed reported various health symptoms and assessed their physical health negatively. Furthermore, a higher percentage of the so-called "cases" according to the GHQ-12 score were recognized among annoyed (or highly annoyed) subjects (Table 7). 
Table 7. Proportions of respondents (with $95 \%$ confidence intervals) who assessed their physical health negatively, being categorized as "cases" based on the GHQ-12 score, and frequently reported various complaints in total and in subgroups of subjects annoyed and not annoyed by the wind turbine noise ${ }^{1}$.

\begin{tabular}{|c|c|c|c|c|c|}
\hline & \multicolumn{5}{|c|}{ Proportion of Respondents (\%) } \\
\hline & \multicolumn{5}{|c|}{$95 \%$ CI } \\
\hline & Total & $\begin{array}{l}\text { Not Annoyed } \\
\text { Outdoors }\end{array}$ & $\begin{array}{l}\text { Annoyed } \\
\text { Outdoors }\end{array}$ & $\begin{array}{c}\text { Not Highly } \\
\text { Annoyed Outdoors }\end{array}$ & $\begin{array}{l}\text { Highly Annoyed } \\
\text { Outdoors }\end{array}$ \\
\hline Negative self-assessment of physical health & $\begin{array}{c}23.0 \\
(19.5-26.8) \\
\end{array}$ & $\begin{array}{c}11.1 \\
(7.8-15.4) \\
\end{array}$ & $\begin{array}{c}36.6 \\
(30.7-42.9) \\
\end{array}$ & $\begin{array}{c}14.2 \\
(11.0-18.2) \\
\end{array}$ & $\begin{array}{c}23.0 \\
(19.5-26.8) \\
\end{array}$ \\
\hline Negative self-assessment of hearing status & $\begin{array}{c}15.2 \\
(12.1-19.1)\end{array}$ & $\begin{array}{c}6.3 \\
(3.7-10.7)\end{array}$ & $\begin{array}{c}24.3 \\
(18.9-30.7)\end{array}$ & $\begin{array}{c}8.2 \\
(5.5-12.1)\end{array}$ & $\begin{array}{c}15.2 \\
(12.1-19.1)\end{array}$ \\
\hline Cases according to the GHQ-12 score & $\begin{array}{c}35.0 \\
(30.6-39.8)\end{array}$ & $\begin{array}{c}19.9 \\
(15.2-25.7)\end{array}$ & $\begin{array}{c}52.6 \\
(45.6-59.6)\end{array}$ & $\begin{array}{c}23.8 \\
(19.3-29.0)\end{array}$ & $\begin{array}{c}35.0 \\
(30.6-39.8)\end{array}$ \\
\hline Headache & $\begin{array}{c}21.3 \\
(18.0-25.0)\end{array}$ & $\begin{array}{c}11.2 \\
(8.0-15.5)\end{array}$ & $\begin{array}{c}32.9 \\
(27.3-39.1)\end{array}$ & $\begin{array}{c}14.5 \\
(11.3-18.5)\end{array}$ & $\begin{array}{c}21.3 \\
(18.0-25.0)\end{array}$ \\
\hline Dizziness & $\begin{array}{c}13.0 \\
(10.3-16.2)\end{array}$ & $\begin{array}{c}5.8 \\
(3.5-9.3)\end{array}$ & $\begin{array}{c}21.3 \\
(16.5-26.9)\end{array}$ & $\begin{array}{c}7.0 \\
(4.8-10.1)\end{array}$ & $\begin{array}{c}13.0 \\
(10.3-16.2)\end{array}$ \\
\hline Heartache & $\begin{array}{c}13.0 \\
(10.3-16.2)\end{array}$ & $\begin{array}{c}5.8 \\
(3.5-9.3)\end{array}$ & $\begin{array}{c}21.3 \\
(16.5-26.9)\end{array}$ & $\begin{array}{c}7.8 \\
(5.5-11.0)\end{array}$ & $\begin{array}{c}13.0 \\
(10.3-16.2)\end{array}$ \\
\hline Fatigue (undue tiredness) & $\begin{array}{c}27.1 \\
(23.4-31.1) \\
\end{array}$ & $\begin{array}{c}14.1 \\
(10.5-18.7) \\
\end{array}$ & $\begin{array}{c}42.1 \\
(36.0-48.4) \\
\end{array}$ & $\begin{array}{c}17.5 \\
(14.0-21.7) \\
\end{array}$ & $\begin{array}{c}27.1 \\
(23.4-31.1) \\
\end{array}$ \\
\hline Insomnia & $\begin{array}{c}19.3 \\
(16.2-23.0)\end{array}$ & $\begin{array}{c}8.3 \\
(5.6-12.2)\end{array}$ & $\begin{array}{c}32.1 \\
(26.5-38.2)\end{array}$ & $\begin{array}{c}9.4 \\
(6.8-12.9)\end{array}$ & $\begin{array}{c}19.3 \\
(16.2-23.0)\end{array}$ \\
\hline $\begin{array}{l}\text { Pain and stiffness in the back, neck } \\
\text { or shoulders }\end{array}$ & $\begin{array}{c}24.2 \\
(20.7-28.1)\end{array}$ & $\begin{array}{c}16.2 \\
(12.4-21.1)\end{array}$ & $\begin{array}{c}33.3 \\
(27.7-39.5)\end{array}$ & $\begin{array}{c}20.2 \\
(16.4-24.6)\end{array}$ & $\begin{array}{c}24.2 \\
(20.7-28.1)\end{array}$ \\
\hline Pulsation in ears & $\begin{array}{c}8.7 \\
(6.6-11.5)\end{array}$ & $\begin{array}{c}1.8 \\
(0.7-4.3)\end{array}$ & $\begin{array}{c}16.7 \\
(12.5-21.9)\end{array}$ & $\begin{array}{c}3.8 \\
(2.2-6.3)\end{array}$ & $\begin{array}{c}8.7 \\
(6.6-11.5)\end{array}$ \\
\hline Dyspnea & $\begin{array}{c}9.5 \\
(7.2-12.3) \\
\end{array}$ & $\begin{array}{c}6.9 \\
(4.4-10.5)\end{array}$ & $\begin{array}{c}12.5 \\
(8.9-17.4)\end{array}$ & $\begin{array}{c}6.2 \\
(4.1-9.2)\end{array}$ & $\begin{array}{c}9.5 \\
(7.2-12.3)\end{array}$ \\
\hline Nervousness, tension or stress & $\begin{array}{c}28.0 \\
(24.4-32.1) \\
\end{array}$ & $\begin{array}{c}16.2 \\
(12.4-21.1) \\
\end{array}$ & $\begin{array}{c}41.7 \\
(35.6-48.0) \\
\end{array}$ & $\begin{array}{c}18.5 \\
(14.9-22.8) \\
\end{array}$ & $\begin{array}{c}28.0 \\
(24.4-32.1) \\
\end{array}$ \\
\hline Tinnitus & $\begin{array}{c}8.3 \\
(6.2-11.0) \\
\end{array}$ & $\begin{array}{c}2.5 \\
(1.1-5.3) \\
\end{array}$ & $\begin{array}{c}15.0 \\
(11.0-20.1) \\
\end{array}$ & $\begin{array}{c}3.5 \\
(2.0-6.0) \\
\end{array}$ & $\begin{array}{c}8.3 \\
(6.2-11.0) \\
\end{array}$ \\
\hline Waking up well rested & $\begin{array}{c}54.2 \\
(49.8-58.4)\end{array}$ & $\begin{array}{c}63.2 \\
(57.3-68.6)\end{array}$ & $\begin{array}{c}43.8 \\
(37.6-50.1)\end{array}$ & $\begin{array}{c}60.2 \\
(55.2-65.1)\end{array}$ & $\begin{array}{c}54.2 \\
(49.8-58.4)\end{array}$ \\
\hline Having difficulty in falling asleep & $\begin{array}{c}25.1 \\
(21.6-29.1) \\
\end{array}$ & $\begin{array}{c}13.4 \\
(9.8-17.9) \\
\end{array}$ & $\begin{array}{c}38.8 \\
(32.8-45.1)\end{array}$ & $\begin{array}{c}15.9 \\
(12.5-19.9)\end{array}$ & $\begin{array}{c}25.1 \\
(21.6-29.1)\end{array}$ \\
\hline Awakened by noise with closed window & $\begin{array}{c}27.3 \\
(23.6-31.3) \\
\end{array}$ & $\begin{array}{c}12.6 \\
(9.2-17.1) \\
\end{array}$ & $\begin{array}{c}44.2 \\
(38.0-50.5) \\
\end{array}$ & $\begin{array}{c}14.8 \\
(11.5-18.8) \\
\end{array}$ & $\begin{array}{c}27.3 \\
(23.6-31.3) \\
\end{array}$ \\
\hline Awakened by noise with open window & $\begin{array}{c}15.1 \\
(12.3-18.5) \\
\end{array}$ & $\begin{array}{c}5.8 \\
(3.5-9.3) \\
\end{array}$ & $\begin{array}{c}25.8 \\
(20.7-31.7) \\
\end{array}$ & $\begin{array}{c}6.2 \\
(4.1-9.2) \\
\end{array}$ & $\begin{array}{c}15.1 \\
(12.3-18.5) \\
\end{array}$ \\
\hline Awakened by wind turbines & $\begin{array}{c}33.7 \\
(29.0-38.7)\end{array}$ & $\begin{array}{c}1.7 \\
(0.4-5.3)\end{array}$ & $\begin{array}{c}62.5 \\
(55.5-69.0)\end{array}$ & $\begin{array}{c}9.5 \\
(6.4-14.0)\end{array}$ & $\begin{array}{c}33.7 \\
(29.0-38.7)\end{array}$ \\
\hline
\end{tabular}

${ }^{1}$ There were statistically significant differences between subgroups of respondents being annoyed (or highly annoyed) and not annoyed (or not highly annoyed), both outdoors and indoors, by the wind turbine noise $(p<0.05)$; GHQ-12-12-item Goldberg's General Health Questionnaire; CI—confidence interval.

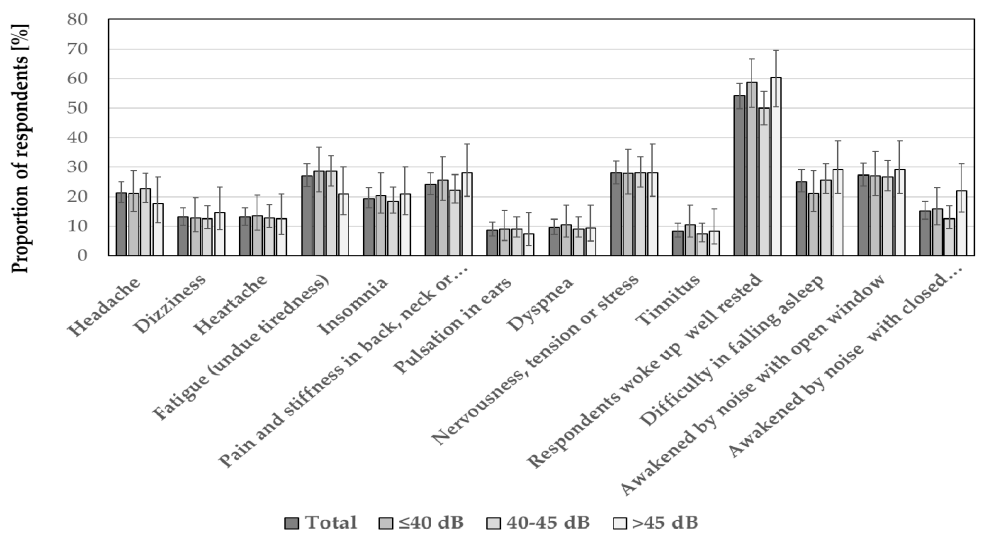

(a)

Figure 6. Cont. 


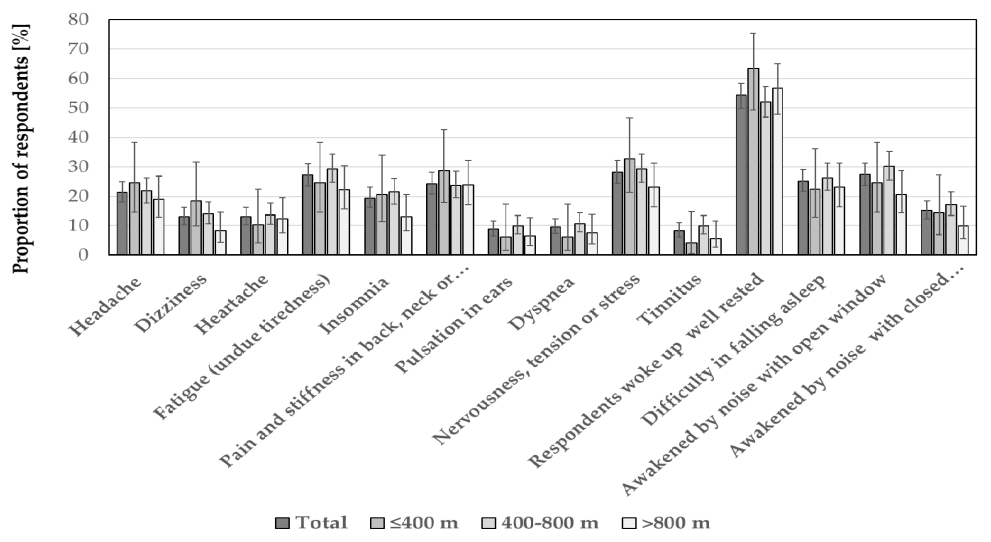

(b)

Figure 6. The prevalence of various health and well-being aspects in total and in each of the: (a) noise and (b) distance categories. Data are presented as proportions with $95 \%$ confidence intervals. There were no significant differences between various noise and distance categories $(p>0.00167)$.

\subsection{Factors Affecting Perception of Annoyance and Self-Reported Health}

According to earlier studies, including our pilot study [17], apart from the noise level (or the distance from the nearest wind turbine) many objective and subjective factors such as respondents' general attitude to wind turbines, sensitivity to landscape littering, financial benefits etc. were found to have a significant impact on the perceived annoyance $[1-3,5,17]$. On the other hand, the prevalence of the health symptoms can vary with age and between males and females. Thus, in order to analyze the influence of various variables (including the noise level and distance) on annoyance and different health aspects related to the wind turbine noise, like in the earlier study $[1,28]$, the binary logistic regression was applied with the logistic model expressed as follows:

$$
p=\frac{e^{\left(b_{0}+b_{1} x_{1}+b_{2} x_{2}+\ldots+b_{n} x_{n}\right)}}{1+e^{\left(b_{0}+b_{1} x_{1}+b_{2} x_{2}+\ldots+b_{n} x_{n}\right)}}
$$

where: $\mathrm{p}$ is the probability of outcome (i.e., being highly annoyed or occurrence of health symptom), $\mathrm{x}_{1}-\mathrm{x}_{\mathrm{n}}$-are the explanatory variables included in the model (e.g., calculated A-weighted sound pressure level), $b_{0}, b_{1}, \ldots b_{n}$-are the regression coefficients, i.e., the logarithmic values of the odds ratio for the unit change in the respective variables.

It is worth noting that this method allows adjustments for known confounders by entering them into regression analyses (e.g., variables age and sex when analyzing the prevalence of health symptoms). An odds ratio (with $95 \%$ confidence interval) above 1.00 indicates a positive correlation between the dependent variable (e.g., health symptoms) and explanatory variable (e.g., noise level or annoyance), while a value below 1.00 indicates a negative correlation between the dependent variable (e.g., annoyance) and explanatory variable (distance or general attitude towards wind turbines).

\subsubsection{Annoyance Related to Wind Turbine Noise}

To analyze the factors affecting annoyance perception, various models were created containing the calculated A-weighted sound pressure level (noise level) at the respondent's dwelling or distance from the nearest turbine as the main potential explanatory variable. Other analyzed explanatory variables were: age (in years), gender ("female" $=0$, "male" $=1$ ), education (1-5), sensitivity to noise or landscape littering (0-4), general attitude to wind farms (0-4), terrain shape ("flat" $=0$, "hilly or mountainous" $=1$ ), road-traffic intensity ("increased intensity" $=0$, "no road-traffic or very low-intensity traffic" $=1)$, time since the start-up of the wind farm (1-11 years), power $(0.132-2.5 \mathrm{MW})$ and height (30-103 $\mathrm{m}$ ) of the nearest wind turbine, economic benefits from the wind farm and having wind turbines visible from the dwelling ("no" $=0$, "yes" $=1$ ). Furthermore, due to more pronounced 
association between noise (or distance) categories and high annoyance, in the following part only the probability of being highly annoyed by the wind turbine noise was analyzed.

In the first step, eight models describing the high annoyance perception (outdoors and indoors) were analyzed (Tables 8 and 9). According to these basic models, the probability of being highly annoyed outdoors was significantly associated with the sound pressure level (or distance), attitude towards wind turbines, sensitivity to noise as well as terrain shape. On the other hand, the annoyance perception indoors was correlated with the noise level (or distance), age, attitude towards wind turbines, sensitivity to noise and traffic intensity. Neither gender nor education had a significant impact on the noise annoyance rating. Likewise, no significant relationships were observed in case of the remaining objective or situational factors.

Table 8. Association between perception outdoors of high annoyance related to the wind turbine noise (dependent, binary variable) and the calculated A-weighted sound pressure level (or distance) as well as subjective (individual) and objective factors (independent variables) tested by logistic regression.

\begin{tabular}{|c|c|c|c|c|c|c|c|c|}
\hline \multirow[b]{2}{*}{ Explanatory Variables } & \multicolumn{8}{|c|}{ High Annoyance Outdoors } \\
\hline & $\begin{array}{l}\text { Odds Ratio } \\
(95 \% \text { CI })\end{array}$ & $p$ & $\begin{array}{l}\text { Odds Ratio } \\
\text { (95\% CI) }\end{array}$ & $p$ & $\begin{array}{c}\text { Odds Ratio } \\
\text { (95\% CI) }\end{array}$ & $p$ & $\begin{array}{l}\text { Odds Ratio } \\
\text { (95\% CI) }\end{array}$ & $p$ \\
\hline Age & $\begin{array}{c}1.01 \\
(0.98-1.03)\end{array}$ & 0.530 & $\begin{array}{c}1.01 \\
(0.98-1.03)\end{array}$ & 0.610 & $\begin{array}{c}1.01 \\
(0.99-1.03)\end{array}$ & 0.461 & $\begin{array}{c}1.01 \\
(0.98-1.03)\end{array}$ & 0.534 \\
\hline Gender & $\begin{array}{c}1.46 \\
(0.77-2.80)\end{array}$ & 0.248 & $\begin{array}{c}1.48 \\
(0.78-2.83)\end{array}$ & 0.234 & $\begin{array}{c}1.41 \\
(0.74-2.68)\end{array}$ & 0.290 & $\begin{array}{c}1.43 \\
(0.75-2.71)\end{array}$ & 0.273 \\
\hline Education & $\begin{array}{c}0.93 \\
(0.68-1.28)\end{array}$ & 0.669 & $\begin{array}{c}0.93 \\
(0.67-1.28)\end{array}$ & 0.650 & $\begin{array}{c}0.93 \\
(0.68-1.29)\end{array}$ & 0.677 & $\begin{array}{c}0.93 \\
(0.68-1.28)\end{array}$ & 0.671 \\
\hline Sensitivity to noise & $\begin{array}{c}1.72 \\
(1.19-2.47)\end{array}$ & 0.004 & $\begin{array}{c}1.74 \\
(1.21-2.52)\end{array}$ & 0.003 & - & - & - & - \\
\hline $\begin{array}{l}\text { Sensitivity to landscape } \\
\text { littering }\end{array}$ & - & - & - & - & $\begin{array}{c}1.32 \\
(0.93-1.86)\end{array}$ & 0.121 & $\begin{array}{c}1.32 \\
(0.93-1.87)\end{array}$ & 0.116 \\
\hline Attitude to wind turbines & $\begin{array}{c}5.02 \\
(3.50-7.21)\end{array}$ & 0.000 & $\begin{array}{c}4.99 \\
(3.48-7.16)\end{array}$ & 0.000 & $\begin{array}{c}4.91 \\
(3.37-7.14)\end{array}$ & 0.000 & $\begin{array}{c}4.88 \\
(3.36-7.09)\end{array}$ & 0.000 \\
\hline Sound pressure level & $\begin{array}{c}1.15 \\
(1.03-1.29)\end{array}$ & 0.014 & - & - & $\begin{array}{c}1.15 \\
(1.02-1.28)\end{array}$ & 0.017 & - & - \\
\hline $\begin{array}{l}\text { Distance from the nearest } \\
\text { wind turbine }\end{array}$ & - & - & $\begin{array}{c}0.13 \\
(0.02-0.75)\end{array}$ & 0.023 & - & - & $\begin{array}{c}0.16 \\
(0.03-0.90)\end{array}$ & 0.038 \\
\hline $\begin{array}{l}\text { Power of the nearest wind } \\
\text { turbine }\end{array}$ & $\begin{array}{c}0.65 \\
(0.18-2.30)\end{array}$ & 0.503 & $\begin{array}{c}0.58 \\
(0.16-2.11)\end{array}$ & 0.411 & $\begin{array}{c}0.74 \\
(0.22-2.52)\end{array}$ & 0.626 & $\begin{array}{c}0.67 \\
(0.19-2.33)\end{array}$ & 0.526 \\
\hline $\begin{array}{l}\text { Height of the nearest wind } \\
\text { turbine }\end{array}$ & $\begin{array}{c}1.02 \\
(0.98-1.06)\end{array}$ & 0.283 & $\begin{array}{c}1.04 \\
(1.00-1.08)\end{array}$ & 0.077 & $\begin{array}{c}1.02 \\
(0.98-1.06)\end{array}$ & 0.370 & $\begin{array}{c}1.03 \\
(0.99-1.08)\end{array}$ & 0.123 \\
\hline $\begin{array}{l}\text { Duration of wind farm } \\
\text { operation }\end{array}$ & $\begin{array}{c}0.86 \\
(0.69-1.07)\end{array}$ & 0.181 & $\begin{array}{c}0.95 \\
(0.78-1.15)\end{array}$ & 0.573 & $\begin{array}{c}0.88 \\
(0.71-1.10)\end{array}$ & 0.260 & $\begin{array}{c}0.97 \\
(0.80-1.17)\end{array}$ & 0.720 \\
\hline $\begin{array}{l}\text { Having turbines visible } \\
\text { from the dwelling }\end{array}$ & $\begin{array}{c}0.34 \\
(0.08-1.48)\end{array}$ & 0.150 & $\begin{array}{c}0.39 \\
(0.09-1.65)\end{array}$ & 0.199 & $\begin{array}{c}0.43 \\
(0.10-1.84)\end{array}$ & 0.255 & $\begin{array}{c}0.49 \\
(0.12-2.04)\end{array}$ & 0.325 \\
\hline Profits from wind turbines & $\begin{array}{c}1.34 \\
(0.32-5.71)\end{array}$ & 0.688 & $\begin{array}{c}1.46 \\
(0.34-6.16)\end{array}$ & 0.609 & $\begin{array}{c}1.17 \\
(0.28-4.94)\end{array}$ & 0.833 & $\begin{array}{c}1.28 \\
(0.30-5.38)\end{array}$ & 0.740 \\
\hline Terrain shape & $\begin{array}{c}2.74 \\
(1.22-6.16)\end{array}$ & 0.015 & $\begin{array}{c}2.53 \\
(1.14-5.60)\end{array}$ & 0.022 & $\begin{array}{c}3.02 \\
(1.36-6.71)\end{array}$ & 0.007 & $\begin{array}{c}2.81 \\
(1.28-6.15)\end{array}$ & 0.010 \\
\hline Road-traffic intensity & $\begin{array}{c}1.43 \\
(0.44-4.70)\end{array}$ & 0.554 & $\begin{array}{c}1.81 \\
(0.59-5.58)\end{array}$ & 0.302 & $\begin{array}{c}1.52 \\
(0.48-4.83)\end{array}$ & 0.479 & $\begin{array}{c}1.87 \\
(0.62-5.62)\end{array}$ & 0.262 \\
\hline
\end{tabular}


Table 9. Association between perception indoors of high annoyance related to the wind turbine noise (dependent, binary variable) and the calculated A-weighted sound pressure level (or distance) as well as subjective (individual) and objective factors (independent variables) tested by logistic regression.

\begin{tabular}{|c|c|c|c|c|c|c|c|c|}
\hline \multirow[b]{2}{*}{ Explanatory Variables } & \multicolumn{8}{|c|}{ High Annoyance Indoors } \\
\hline & $\begin{array}{l}\text { Odds Ratio } \\
(95 \% \text { CI })\end{array}$ & $p$ & $\begin{array}{l}\text { Odds Ratio } \\
\text { (95\% CI) }\end{array}$ & $p$ & $\begin{array}{l}\text { Odds Ratio } \\
(95 \% \text { CI })\end{array}$ & $p$ & $\begin{array}{l}\text { Odds Ratio } \\
\text { (95\% CI) }\end{array}$ & $p$ \\
\hline Age & $\begin{array}{c}1.03 \\
(1.00-1.05)\end{array}$ & 0.026 & $\begin{array}{c}1.02 \\
(1.00-1.05)\end{array}$ & 0.031 & $\begin{array}{c}1.03 \\
(1.00-1.05)\end{array}$ & 0.023 & $\begin{array}{c}1.02 \\
(1.00-1.05)\end{array}$ & 0.028 \\
\hline Gender & $1.14(0.62-2.12)$ & 0.672 & $\begin{array}{c}1.15 \\
(0.62-2.13)\end{array}$ & 0.653 & $\begin{array}{c}1.12 \\
(0.61-2.07)\end{array}$ & 0.715 & $\begin{array}{c}1.13 \\
(0.61-2.09)\end{array}$ & 0.688 \\
\hline Education & $\begin{array}{c}1.23 \\
(0.90-1.68)\end{array}$ & 0.203 & $\begin{array}{c}1.23 \\
(0.89-1.68)\end{array}$ & 0.206 & $\begin{array}{c}1.20 \\
(0.87-1.65)\end{array}$ & 0.265 & $\begin{array}{c}1.20 \\
(0.88-1.66)\end{array}$ & 0.253 \\
\hline Sensitivity to noise & $\begin{array}{c}1.50 \\
(1.03-2.17)\end{array}$ & 0.033 & $\begin{array}{c}1.51 \\
(1.04-2.19)\end{array}$ & 0.032 & - & - & - & - \\
\hline $\begin{array}{l}\text { Sensitivity to landscape } \\
\text { littering }\end{array}$ & - & - & - & - & $\begin{array}{c}1.34 \\
(0.94-1.92)\end{array}$ & 0.103 & $\begin{array}{c}1.32 \\
(0.93-1.89)\end{array}$ & 0.121 \\
\hline Attitude to wind turbines & $\begin{array}{c}3.43 \\
(2.44-4.82)\end{array}$ & 0.000 & $\begin{array}{c}3.39 \\
(2.41-4.76)\end{array}$ & 0.000 & $\begin{array}{c}3.38 \\
(2.37-4.82)\end{array}$ & 0.000 & $\begin{array}{c}3.37 \\
(2.36-4.80)\end{array}$ & 0.000 \\
\hline Sound pressure level & $\begin{array}{c}1.12 \\
(1.01-1.24)\end{array}$ & 0.040 & - & - & $\begin{array}{c}1.11 \\
(1.00-1.24)\end{array}$ & 0.043 & - & - \\
\hline $\begin{array}{l}\text { Distance from the nearest } \\
\text { wind turbine }\end{array}$ & - & - & $\begin{array}{c}0.22 \\
(0.04-1.22)\end{array}$ & 0.083 & - & - & $\begin{array}{c}0.25 \\
(0.05-1.38)\end{array}$ & 0.112 \\
\hline $\begin{array}{c}\text { Power of the nearest wind } \\
\text { turbine }\end{array}$ & $\begin{array}{c}1.11 \\
(0.33-3.72)\end{array}$ & 0.867 & $\begin{array}{c}0.99 \\
(0.27-3.70)\end{array}$ & 0.989 & $\begin{array}{c}1.18 \\
(0.35-3.96)\end{array}$ & 0.784 & $\begin{array}{c}1.07 \\
(0.32-3.61)\end{array}$ & 0.917 \\
\hline $\begin{array}{l}\text { Height of the nearest wind } \\
\text { turbine }\end{array}$ & $\begin{array}{c}1.01 \\
(0.97-1.05)\end{array}$ & 0.679 & $\begin{array}{c}1.02 \\
(0.98-1.06)\end{array}$ & 0.351 & $\begin{array}{c}1.01 \\
(0.97-1.05)\end{array}$ & 0.768 & $\begin{array}{c}1.02 \\
(0.98-1.06)\end{array}$ & 0.411 \\
\hline $\begin{array}{c}\text { Duration of wind farm } \\
\text { operation }\end{array}$ & $\begin{array}{c}0.97 \\
(0.82-1.16)\end{array}$ & 0.750 & $\begin{array}{c}1.03 \\
(0.89-1.21)\end{array}$ & 0.668 & $\begin{array}{c}0.99 \\
(0.83-1.18)\end{array}$ & 0.917 & $\begin{array}{c}1.05 \\
(0.90-1.23)\end{array}$ & 0.513 \\
\hline $\begin{array}{l}\text { Having turbines visible } \\
\text { from the dwelling }\end{array}$ & $\begin{array}{c}0.75 \\
(0.15-3.74)\end{array}$ & 0.725 & $\begin{array}{c}0.80 \\
(0.16-3.88)\end{array}$ & 0.781 & $\begin{array}{c}0.82 \\
(0.17-4.04)\end{array}$ & 0.810 & $\begin{array}{c}0.89 \\
(0.19-4.20)\end{array}$ & 0.878 \\
\hline Profits from wind turbines & $\begin{array}{c}0.67 \\
(0.29-1.55)\end{array}$ & 0.354 & $0.68(0.30-1.56)$ & 0.361 & $\begin{array}{c}0.75 \\
(0.33-1.71)\end{array}$ & 0.492 & $\begin{array}{c}0.76 \\
(0.33-1.71)\end{array}$ & 0.503 \\
\hline Terrain shape & $\begin{array}{c}0.99 \\
(0.21-4.63)\end{array}$ & 0.986 & $1.03(0.22-4.79)$ & 0.965 & $\begin{array}{c}0.96 \\
(0.21-4.37)\end{array}$ & 0.954 & $\begin{array}{c}1.01 \\
(0.22-4.66)\end{array}$ & 0.990 \\
\hline Road-traffic intensity & $\begin{array}{c}3.65 \\
(1.06-12.61)\end{array}$ & 0.04 & $3.96(1.18-13.32)$ & 0.026 & $\begin{array}{c}3.81 \\
(1.11-13.09)\end{array}$ & 0.033 & $\begin{array}{c}4.11 \\
(1.23-13.76)\end{array}$ & 0.022 \\
\hline
\end{tabular}

In the second step, various models (describing the probability of being highly annoyed by the wind turbine outdoors and indoors) were created taking into account the aforesaid independent variables, including those containing only the sound pressure level or distance as explanatory variables (Tables 10 and 11). It is worth emphasizing that majority regression coefficients in these models, excluding some regression coefficients for the sound pressure level and distance, reached statistical significance (see models numbered 13 and 14 in Table 10 and models 1, 3 and 6 in Table 11).

Table 10. Factors affecting the noise annoyance perception outdoors-results of logistic regression analyses ${ }^{1}$.

\begin{tabular}{|c|c|c|c|c|c|}
\hline \multirow{2}{*}{ Explanatory Variable } & \multirow{2}{*}{ Model No. } & Odds Ratio(95\% CI) & $p$ & Pseudo- $R^{2}$ & CCR \\
\hline & & \multicolumn{4}{|c|}{ High Annoyance Outdoors } \\
\hline Distance & \multirow{4}{*}{1} & $0.11(0.02-0.52)$ & 0.006 & \multirow{4}{*}{0.659} & \multirow{4}{*}{87.7} \\
\hline Traffic intensity & & $4.23(2.25-7.97)$ & 0.000 & & \\
\hline Attitude to wind turbines & & $5.45(3.88-7.64)$ & 0.000 & & \\
\hline Sensitivity to noise & & $1.56(1.11-2.21)$ & 0.012 & & \\
\hline Distance & \multirow{3}{*}{2} & $0.11(0.02-0.51)$ & 0.005 & \multirow{3}{*}{0.645} & \multirow{3}{*}{87.5} \\
\hline Attitude to wind turbines & & $4.43(2.40-8.19)$ & 0.000 & & \\
\hline Sensitivity to noise & & $6.09(4.37-8.48)$ & 0.000 & & \\
\hline Distance & \multirow{3}{*}{3} & $0.18(0.04-0.78)$ & 0.022 & \multirow{3}{*}{0.625} & \multirow{3}{*}{87.3} \\
\hline Traffic intensity & & $5.94(4.24-8.34)$ & 0.000 & & \\
\hline Attitude to wind turbines & & $1.69(1.21-2.36)$ & 0.002 & & \\
\hline Distance & \multirow[b]{2}{*}{4} & $0.18(0.04-0.75)$ & 0.019 & \multirow[b]{2}{*}{0.606} & \multirow{2}{*}{87.3} \\
\hline Attitude to wind turbines & & $6.77(4.85-9.44)$ & 0.000 & & \\
\hline Distance & \multirow{2}{*}{5} & $0.28(0.09-0.83)$ & 0.021 & \multirow{2}{*}{0.214} & \multirow{2}{*}{75.4} \\
\hline Sensitivity to noise & & $2.63(2.02-3.43)$ & 0.000 & & \\
\hline Distance & \multirow{3}{*}{$\begin{array}{l}6 \\
7\end{array}$} & $0.29(0.10-0.86)$ & 0.027 & \multirow{2}{*}{0.174} & \multirow[b]{2}{*}{72.7} \\
\hline Traffic intensity & & $5.34(3.40-8.39)$ & 0.000 & & \\
\hline Distance & & $0.33(0.12-0.92)$ & 0.034 & 0.013 & 72.0 \\
\hline
\end{tabular}


Table 10. Cont.

\begin{tabular}{|c|c|c|c|c|c|}
\hline \multirow{2}{*}{ Explanatory Variable } & \multirow{2}{*}{ Model No. } & Odds Ratio(95\% CI) & $p$ & Pseudo- $R^{2}$ & CCR \\
\hline & & \multicolumn{4}{|c|}{ High Annoyance Outdoors } \\
\hline Sound pressure level & \multirow{4}{*}{8} & $1.14(1.03-1.25)$ & 0.008 & \multirow{4}{*}{0.658} & \multirow{4}{*}{87.5} \\
\hline Traffic intensity & & $4.08(2.19-7.60)$ & 0.000 & & \\
\hline Attitude to wind turbines & & $5.62(3.98-7.92)$ & 0.000 & & \\
\hline Sensitivity to noise & & $1.54(1.09-2.17)$ & 0.014 & & \\
\hline Sound pressure level & \multirow{3}{*}{9} & $1.15(1.05-1.27)$ & 0.003 & \multirow{3}{*}{0.646} & \multirow{3}{*}{88.1} \\
\hline Attitude to wind turbines & & $4.31(2.35-7.90)$ & 0.000 & & \\
\hline Sensitivity to noise & & $6.32(4.50-8.87)$ & 0.000 & & \\
\hline Sound pressure level & \multirow{3}{*}{10} & $1.11(1.02-1.22)$ & 0.023 & \multirow{3}{*}{0.625} & \multirow{3}{*}{86.3} \\
\hline Traffic intensity & & $6.01(4.28-8.44)$ & 0.000 & & \\
\hline Attitude to wind turbines & & $1.68(1.21-2.34)$ & 0.002 & & \\
\hline Sound pressure level & \multirow[b]{2}{*}{11} & $1.13(1.03-1.23)$ & 0.010 & \multirow[b]{2}{*}{0.608} & \multirow[b]{2}{*}{86.5} \\
\hline Attitude to wind turbines & & $6.87(4.91-9.60)$ & 0.000 & & \\
\hline Sound pressure level & \multirow{2}{*}{12} & $0.28(0.09-0.83)$ & 0.021 & \multirow{2}{*}{0.214} & \multirow{2}{*}{75.4} \\
\hline Sensitivity to noise & & $2.63(2.02-3.43)$ & 0.000 & & \\
\hline Sound pressure level & \multirow[b]{2}{*}{13} & $1.06(1.00-1.13)$ & 0.071 & \multirow[b]{2}{*}{0.170} & \multirow[b]{2}{*}{72.0} \\
\hline Traffic intensity & & $5.29(3.37-8.29)$ & 0.000 & & \\
\hline Sound pressure level & 14 & $1.09(1.01-1.17)$ & 0.071 & 0.009 & 72.0 \\
\hline
\end{tabular}

1 Various models were created with the sound pressure level (or distance) and attitude to wind turbines, noise sensitivity and terrain shape as possible explanatory variables; Pseudo- $\mathrm{R}^{2}$ - the Nagelkerke coefficient of determination, i.e., a measure of explained variance [25]; CCR - correct classification rate; $\mathrm{CI}$-confidence interval.

Table 11. Factors affecting noise annoyance perception indoors—results of logistic regression analyses ${ }^{1}$.

\begin{tabular}{|c|c|c|c|c|c|}
\hline \multirow{2}{*}{ Explanatory Variable } & \multirow{2}{*}{ Model No. } & Odds Ratio $(95 \%$ CI $)$ & $p$ & Pseudo- $^{2}$ & CCR \\
\hline & & \multicolumn{4}{|c|}{ High Annoyance Indoors } \\
\hline Distance & \multirow{4}{*}{1} & $0.29(0.06-1.29)$ & 0.103 & \multirow{4}{*}{0.476} & \multirow{4}{*}{86.7} \\
\hline Traffic intensity & & $3.43(1.33-8.84)$ & 0.011 & & \\
\hline Attitude to wind turbines & & $3.40(2.51-4.61)$ & 0.000 & & \\
\hline Sensitivity to noise & & $1.51(1.05-2.16)$ & 0.024 & & \\
\hline Distance & \multirow{3}{*}{2} & $0.21(0.05-0.93)$ & 0.040 & \multirow{3}{*}{0.458} & \multirow{3}{*}{86.5} \\
\hline Attitude to wind turbines & & $3.73(2.76-5.05)$ & 0.000 & & \\
\hline Sensitivity to noise & & $1.47(1.04-2.08)$ & 0.028 & & \\
\hline Distance & \multirow{3}{*}{3} & $0.27(0.06-1.20)$ & 0.085 & \multirow{3}{*}{0.463} & \multirow{3}{*}{87.1} \\
\hline Traffic intensity & & $3.21(1.26-8.13)$ & 0.014 & & \\
\hline Attitude to wind turbines & & $3.90(2.90-5.24)$ & 0.000 & & \\
\hline Distance & \multirow[b]{2}{*}{4} & $0.20(0.04-0.90)$ & 0.036 & \multirow[b]{2}{*}{0.446} & \multirow[b]{2}{*}{87.3} \\
\hline Attitude to wind turbines & & $4.27(3.18-5.71)$ & 0.000 & & \\
\hline Distance & \multirow{2}{*}{5} & $0.22(0.06-0.76)$ & 0.017 & \multirow[b]{2}{*}{0.168} & \multirow{2}{*}{69.9} \\
\hline Sensitivity to noise & & $2.50(1.83-3.40)$ & 0.000 & & \\
\hline Distance & \multirow[b]{2}{*}{6} & $0.34(0.10-1.18)$ & 0.089 & \multirow{2}{*}{0.125} & \multirow{2}{*}{81.6} \\
\hline Traffic intensity & & $7.59(3.23-17.85)$ & 0.000 & & \\
\hline Distance & 7 & $0.23(0.07-0.77)$ & 0.017 & 0.019 & 81.6 \\
\hline Sound pressure level & \multirow{4}{*}{8} & $1.10(1.00-1.20)$ & 0.039 & \multirow{4}{*}{0.480} & \multirow{4}{*}{86.7} \\
\hline Traffic intensity & & $3.72(1.45-9.52)$ & 0.006 & & \\
\hline Attitude to wind turbines & & $3.41(2.52-4.61)$ & 0.000 & & \\
\hline Sensitivity to noise & & $1.50(1.05-2.14)$ & 0.027 & & \\
\hline Sound pressure level & \multirow{3}{*}{9} & $1.10(1.01-1.20)$ & 0.033 & \multirow{3}{*}{0.458} & \multirow{3}{*}{63.4} \\
\hline Attitude to wind turbines & & $3.76(2.78-5.09)$ & 0.000 & & \\
\hline Sensitivity to noise & & $1.46(1.04-2.05)$ & 0.031 & & \\
\hline Sound pressure level & \multirow{3}{*}{10} & $1.11(1.01-1.21)$ & 0.025 & & \\
\hline Traffic intensity & & $3.52(1.40-8.87)$ & 0.008 & 0.468 & 87.1 \\
\hline Attitude to wind turbines & & $3.89(2.90-5.22)$ & 0.000 & & \\
\hline Sound pressure level & & $1.11(1.01-1.21)$ & 0.024 & & \\
\hline Attitude to wind turbines & 11 & $4.29(3.20-5.75)$ & 0.000 & 0.448 & 87.5 \\
\hline Sound pressure level & & $1.08(1.01-1.17)$ & 0.031 & & \\
\hline Sensitivity to noise & 12 & $2.48(1.82-3.37)$ & 0.000 & 0.164 & 81.0 \\
\hline Sound pressure level & 13 & $1.08(1.01-1.16)$ & 0.029 & 0130 & 877 \\
\hline Traffic intensity & 13 & $7.96(3.39-18.70)$ & 0.000 & 0.130 & 87.1 \\
\hline Sound pressure level & 14 & 1.09 (1.01-1.17) & 0.022 & 0.017 & 81.6 \\
\hline
\end{tabular}

${ }^{1}$ Various models were created with the sound pressure level (or distance) and attitude to wind turbines, noise sensitivity and road-traffic intensity as possible explanatory variables; Pseudo- $\mathrm{R}^{2}$ - the Nagelkerke coefficient of determination, i.e., a measure of explained variance [25]; CCR—correct classification rate. CI—confidence interval. 
When analyzing the probability of being highly annoyed outdoors, the highest values of pseudo- $R^{2}$ equal to approximately 0.66 were obtained for models No. 1 and 8 (see Table 10), indicating that the sound pressure level (or distance), terrain shape, sensitivity to noise and general attitude to wind turbines explained $66 \%$ of variance in annoyance assessment. Similar results, i.e., pseudo- $\mathrm{R}^{2}$ of $0.60-0.65$, were obtained for models No. $2-4$ and $8-11$, in particular those containing only noise level (or distance) and general attitude to wind turbines as explanatory variables (model No. 4). On the other hand, the distance itself explained only about $1 \%$ of the variance in perceived annoyance (see model No. 7 in Table 10).

Similar relationships were obtained when studying the noise annoyance perception indoors (Table 13). However, in this case, instead of the terrain shape, the road-traffic intensity was taken into consideration. Furthermore, the highest value of explained variance in annoyance equal to approximately $48 \%$ was obtained for the model containing the attitude to wind turbine, sensitivity to noise, road-traffic intensity and noise level as explanatory variables. In turn, distance (or sound pressure level) itself explained only about $2 \%$ of the variance in perceived high annoyance indoors (see models no. 8 and 14 in Table 11).

The odds ratio of being annoyed (or highly annoyed) by the wind turbine noise (both outdoors and indoors) increased with an increasing noise level (OR $>1.00)$, higher sensitivity to noise (OR $>1.00)$ and more negative attitude towards wind turbines, and decreased with an increasing distance from the nearest wind turbine $(\mathrm{OR}<1.00)$, provided that the regression coefficients reached a statistical significance. Likewise, hilly or mountainous (vs. flat) terrain and no or low-intensity (vs. increased intensity) road-traffic increased the risk of being annoyed outdoors and indoors, respectively.

\subsubsection{Exposure-Response Relationships}

Results of the logistic regression analysis were also a basis for determination of exposure-response relationships expressed as probability (percentage) of subjects being highly annoyed outdoors or indoors versus noise level (or distance) and other variables.

Tables 12 and 13 present the estimates of regression coefficient $\beta_{i}$ (with estimated standard errors) for the aforesaid models, while Figures 7-10 show the exposure-response curves corresponding to models for which all regression coefficients reached a statistical significance. These curves were drawn, where applicable, with explanatory variables such as the terrain shape (or road-traffic intensity), sensitivity to noise and attitude to wind turbines equal to median values in this study population. 
Table 12. Estimated coefficients for various logistic models of high annoyance due to the wind turbine noise outdoors.

\begin{tabular}{|c|c|c|c|c|c|c|c|c|c|c|c|c|c|c|c|}
\hline & Constant & SE & $p$ & Distance & $\mathrm{SE}$ & $p$ & Terrain Shape & SE & $p$ & $\begin{array}{c}\text { Attitude to } \\
\text { Wind Turbines }\end{array}$ & SE & $p$ & $\begin{array}{l}\text { Sensitivity to } \\
\text { Noise }\end{array}$ & SE & $p$ \\
\hline 1 & -5.494 & 0.768 & 0.000 & -2.218 & 0.796 & 0.006 & 1.443 & 0.322 & 0.000 & 1.695 & 0.172 & 0.000 & 0.446 & 0.176 & 0.012 \\
\hline 2 & -4.581 & 0.650 & 0.000 & -2.212 & 0.781 & 0.005 & 1.489 & 0.313 & 0.000 & 1.806 & 0.168 & 0.000 & - & - & - \\
\hline 3 & -5.409 & 0.758 & 0.000 & -1.717 & 0.748 & 0.022 & - & - & - & 1.782 & 0.172 & 0.000 & 0.525 & 0.170 & 0.002 \\
\hline 4 & -4.290 & 0.632 & 0.000 & -1.725 & 0.732 & 0.019 & - & - & - & 1.912 & 0.170 & 0.000 & - & - & - \\
\hline 5 & -1.148 & 0.402 & 0.004 & -1.244 & 0.559 & 0.027 & 1.676 & 0.230 & 0.000 & - & - & - & - & - & - \\
\hline 6 & -2.788 & 0.540 & 0.000 & -1.277 & 0.554 & 0.022 & - & - & - & - & - & - & 0.968 & 0.135 & 0.000 \\
\hline \multirow[t]{2}{*}{7} & -0.208 & 0.354 & 0.556 & -1.119 & 0.525 & 0.034 & - & - & - & - & - & - & - & - & - \\
\hline & Constant & SE & $p$ & $\begin{array}{c}\text { Sound Pressure } \\
\text { Level }\end{array}$ & SE & $p$ & Terrain Shape & SE & $p$ & $\begin{array}{c}\text { Attitude to } \\
\text { Wind Turbines }\end{array}$ & SE & $p$ & $\begin{array}{l}\text { Sensitivity } \\
\text { Noise }\end{array}$ & SE & $p$ \\
\hline 8 & -12.368 & 2.258 & 0.000 & 0.129 & 0.048 & 0.008 & 1.405 & 0.317 & 0.000 & 1.726 & 0.175 & 0.000 & 0.431 & 0.174 & 0.014 \\
\hline 9 & -12.046 & 2.200 & 0.000 & 0.141 & 0.048 & 0.003 & 1.461 & 0.308 & 0.000 & 1.844 & 0.172 & 0.000 & - & - & - \\
\hline 10 & -11.067 & 2.141 & 0.000 & 0.107 & 0.047 & 0.023 & - & - & - & 1.794 & 0.173 & 0.000 & 0.519 & 0.168 & 0.002 \\
\hline 11 & -10.496 & 2.066 & 0.000 & 0.120 & 0.046 & 0.010 & - & - & - & 1.927 & 0.171 & 0.000 & - & - & - \\
\hline 12 & -6.112 & 1.480 & 0.000 & 0.059 & 0.033 & 0.075 & - & - & - & - & - & - & 0.961 & 0.134 & 0.000 \\
\hline 13 & -4.375 & 1.356 & 0.001 & 0.057 & 0.032 & 0.071 & 1.666 & 0.229 & 0.000 & - & - & - & - & - & - \\
\hline 14 & -3.354 & 1.338 & 0.013 & 0.057 & 0.032 & 0.071 & - & - & - & - & - & - & - & - & - \\
\hline
\end{tabular}


Table 13. Estimated coefficients for various logistic models of high annoyance due to the wind turbine noise indoors.

\begin{tabular}{|c|c|c|c|c|c|c|c|c|c|c|c|c|c|c|c|}
\hline Model No. & Constant & $\mathrm{SE}$ & $p$ & Distance & SE & $p$ & $\begin{array}{c}\text { Traffic } \\
\text { Intensity }\end{array}$ & SE & $p$ & $\begin{array}{c}\text { Attitude to } \\
\text { Wind Turbines }\end{array}$ & $\mathrm{SE}$ & $p$ & $\begin{array}{l}\text { Sensitivity to } \\
\text { Noise }\end{array}$ & SE & $p$ \\
\hline 1 & -5.904 & 0.911 & 0.000 & -1.247 & 0.764 & 0.103 & 1.231 & 0.482 & 0.011 & 1.224 & 0.154 & 0.000 & 0.411 & 0.182 & 0.024 \\
\hline 2 & -4.846 & 0.770 & 0.000 & -1.556 & 0.757 & 0.040 & - & - & - & 1.316 & 0.154 & 0.000 & 0.386 & 0.176 & 0.028 \\
\hline 3 & -4.994 & 0.785 & 0.000 & -1.328 & 0.769 & 0.085 & 1.165 & 0.474 & 0.014 & 1.361 & 0.150 & 0.000 & - & - & - \\
\hline 4 & -4.076 & 0.670 & 0.000 & -1.613 & 0.766 & 0.036 & - & - & - & 1.451 & 0.149 & 0.000 & - & - & - \\
\hline 5 & -3.111 & 0.636 & 0.000 & -1.519 & 0.636 & 0.017 & - & - & - & - & - & - & 0.915 & 0.158 & 0.000 \\
\hline 6 & -2.472 & 0.592 & 0.000 & -1.065 & 0.625 & 0.089 & 2.027 & 0.435 & 0.000 & - & - & - & - & - & - \\
\hline \multirow[t]{2}{*}{7} & -0.528 & 0.408 & 0.196 & -1.486 & 0.620 & 0.017 & - & - & - & - & - & - & - & - & - \\
\hline & Constant & $\mathrm{SE}$ & $p$ & $\begin{array}{c}\text { Sound Pressure } \\
\text { Level }\end{array}$ & SE & $p$ & $\begin{array}{c}\text { Traffic } \\
\text { Intensity }\end{array}$ & SE & $p$ & $\begin{array}{c}\text { Attitude to } \\
\text { Wind Turbines }\end{array}$ & SE & $p$ & $\begin{array}{l}\text { Sensitivity to } \\
\text { Noise }\end{array}$ & SE & $p$ \\
\hline 8 & -10.701 & 2.059 & 0.000 & 0.093 & 0.045 & 0.039 & 1.314 & 0.478 & 0.006 & 1.225 & 0.154 & 0.000 & 0.403 & 0.182 & 0.027 \\
\hline 9 & -9.903 & 2.013 & 0.000 & 0.096 & 0.045 & 0.033 & - & - & - & 1.325 & 0.154 & 0.000 & 0.378 & 0.174 & 0.031 \\
\hline 10 & -10.170 & 2.009 & 0.000 & 0.101 & 0.045 & 0.025 & 1.258 & 0.470 & 0.008 & 1.359 & 0.150 & 0.000 & - & - & - \\
\hline 11 & -9.415 & 1.967 & 0.000 & 0.101 & 0.045 & 0.024 & - & - & - & 1.457 & 0.149 & 0.000 & - & - & - \\
\hline 12 & -7.502 & 1.682 & 0.000 & 0.081 & 0.038 & 0.031 & - & - & - & - & - & - & 0.908 & 0.157 & 0.000 \\
\hline 13 & -6.533 & 1.584 & 0.000 & 0.079 & 0.036 & 0.029 & 2.075 & 0.434 & 0.000 & - & - & - & - & - & - \\
\hline 14 & -5.075 & 1.574 & 0.001 & 0.085 & 0.037 & 0.022 & - & - & - & - & - & - & - & - & - \\
\hline
\end{tabular}




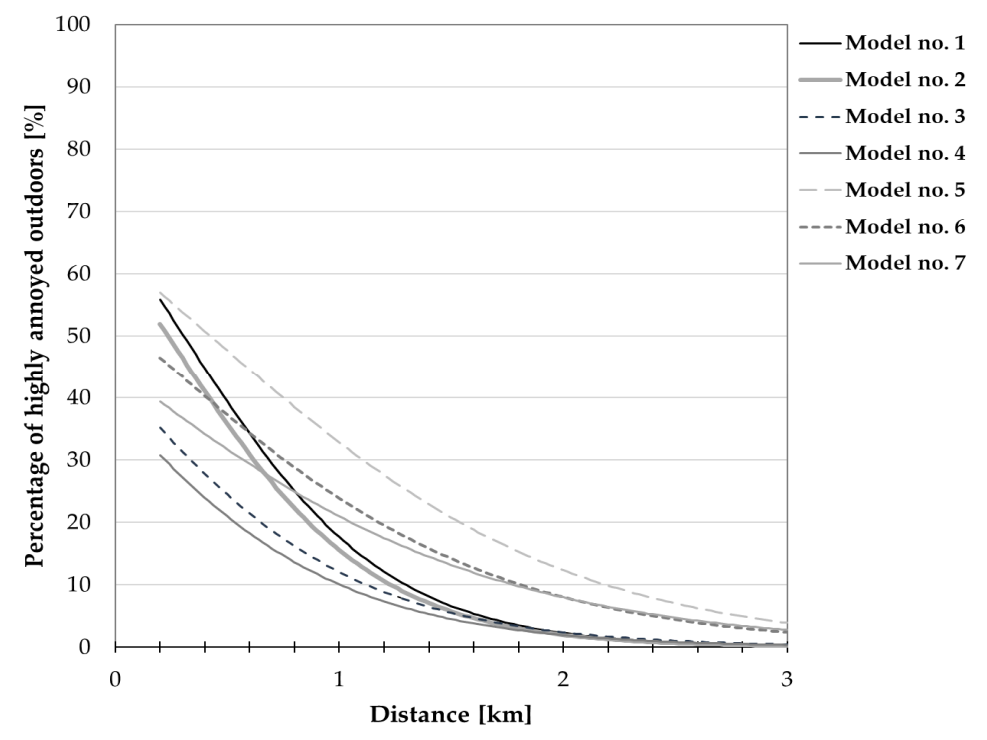

(a)

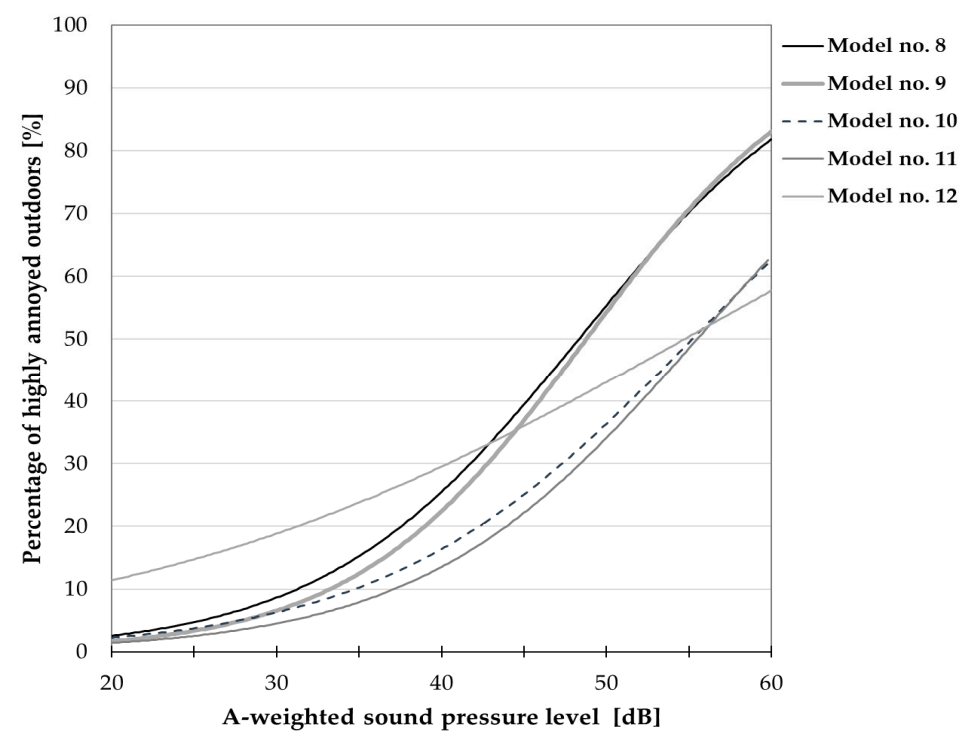

(b)

Figure 7. Relationships between the percentage of respondents being highly annoyed outdoors and (a) noise level or (b) distance from the nearest wind turbine. The curves correspond only to those models from Table 12 for which all regression coefficients reached a statistical significance; they were drawn, where applicable, with explanatory variables of "terrain shape" $(=1)$, "sensitivity to noise" $(=3)$ and "attitude to wind farms" (=2) equal to median values in the study group. 


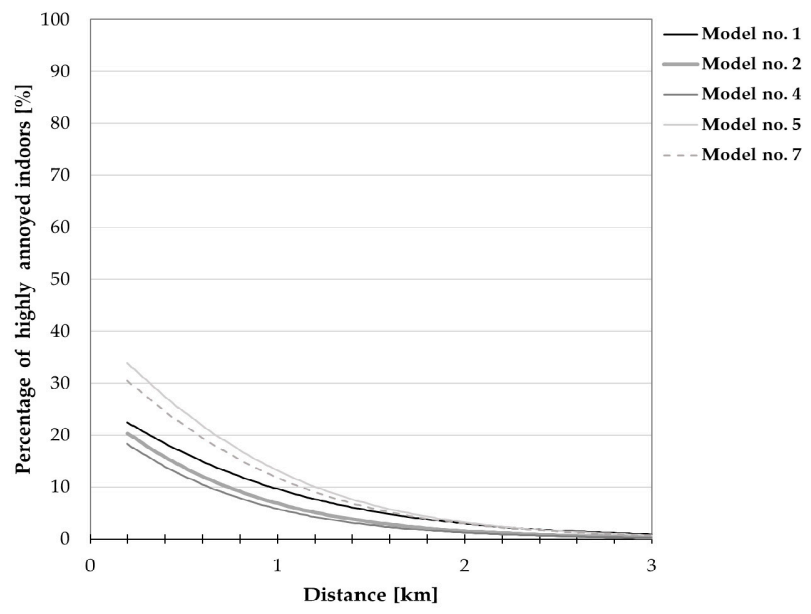

(a)

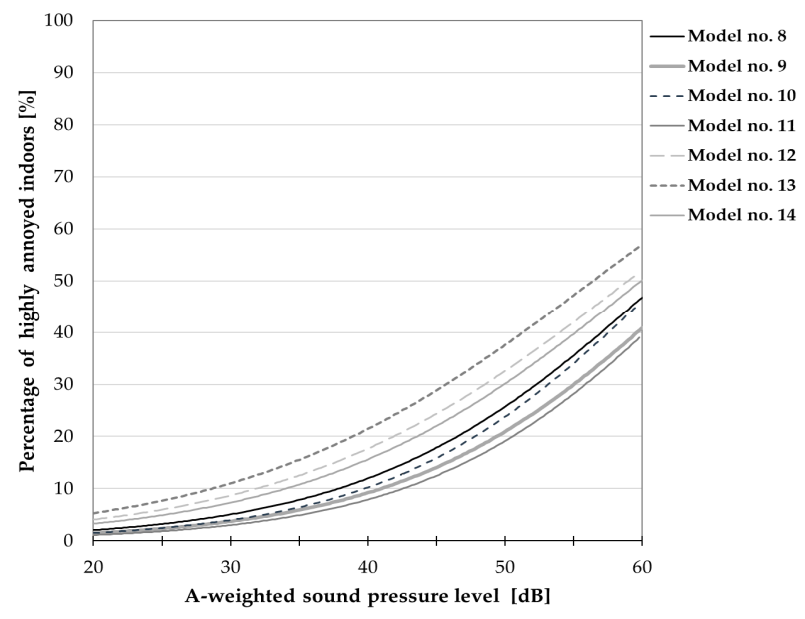

(b)

Figure 8. Relationships between the percentage of respondents being highly annoyed indoors and (a) noise level or (b) distance from the nearest wind turbine. The curves correspond only to those models from Table 13 for which all regression coefficients reached a statistical significance; they were drawn, where applicable, with explanatory variables of "road-traffic intensity" $(=1)$, "sensitivity to noise" (=3) and "attitude to wind farms" (=2) equal to median values in the study group.

On the other hand, Figures 9 and 10 present exposure-response curves which take into consideration, apart from the noise level (or distance), a general opinion about wind turbines. According to these curves, namely those corresponding to model no. 4 in Table 12 (Figure 9a) at the distance of $1000 \mathrm{~m}$, the wind turbine noise might be perceived as highly annoying outdoors by approximately $2 \%$ and $43 \%$ of people with positive and negative attitudes towards wind farms, respectively. At the same distance, up to $21 \%$ of the subjects (with negative attitude to wind farms) might be highly annoyed by the wind turbine noise indoors (see Figure 10a, model No. 4 in Table 13). On the other hand, in areas where the A-weighted sound pressure level exceeds $40 \mathrm{~dB}$, above 2 and $52 \%$ of people with a positive and negative attitude to wind farms, respectively, might be highly annoyed outdoors (see Figure 9b, model no. 11 in Table 12). At such noise levels, above 27\% of subjects with a negative opinion about wind farms might be annoyed indoors (see Figure 10b, model no. 11 in Table 13). However, regardless of the noise level or distance from the nearest wind turbine, a much lower percentage of the subjects who are indifferent to wind farms might perceive the wind turbine noise as highly annoying (Figures 9 and 10). 


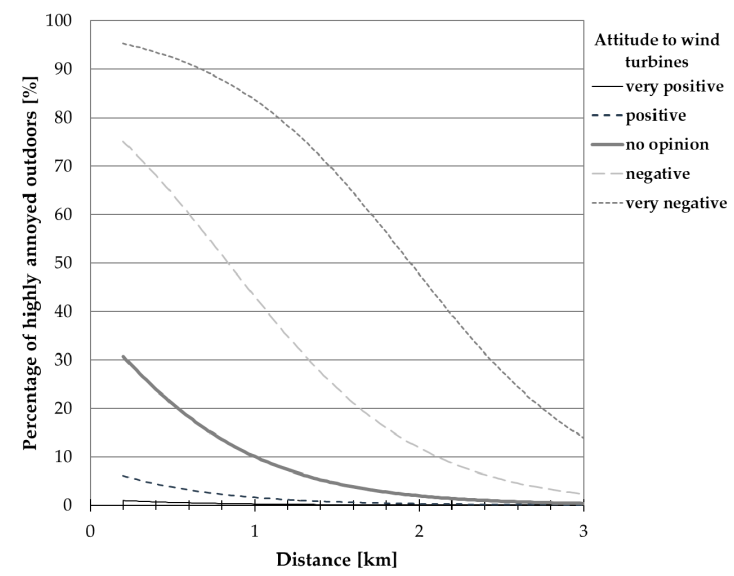

(a)

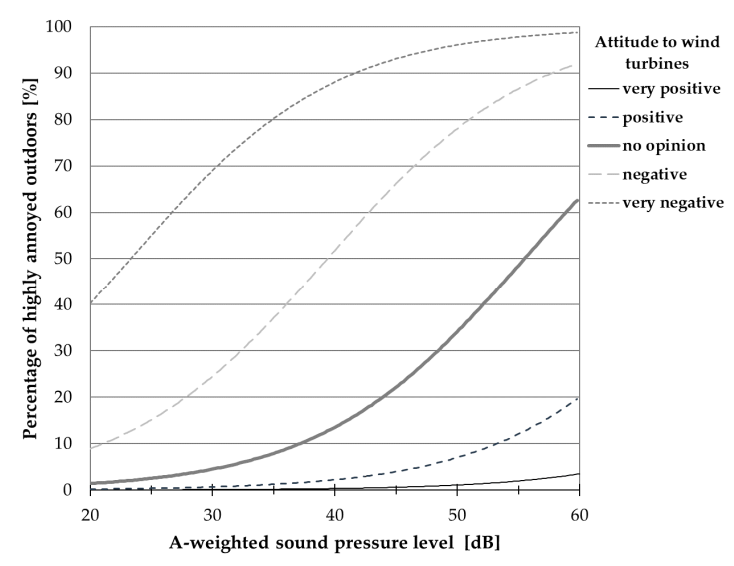

(b)

Figure 9. Percentage of respondents being highly annoyed outdoors by the wind turbine noise as a function of attitude to wind farms and (a) noise level or (b) distance from the nearest wind turbine.

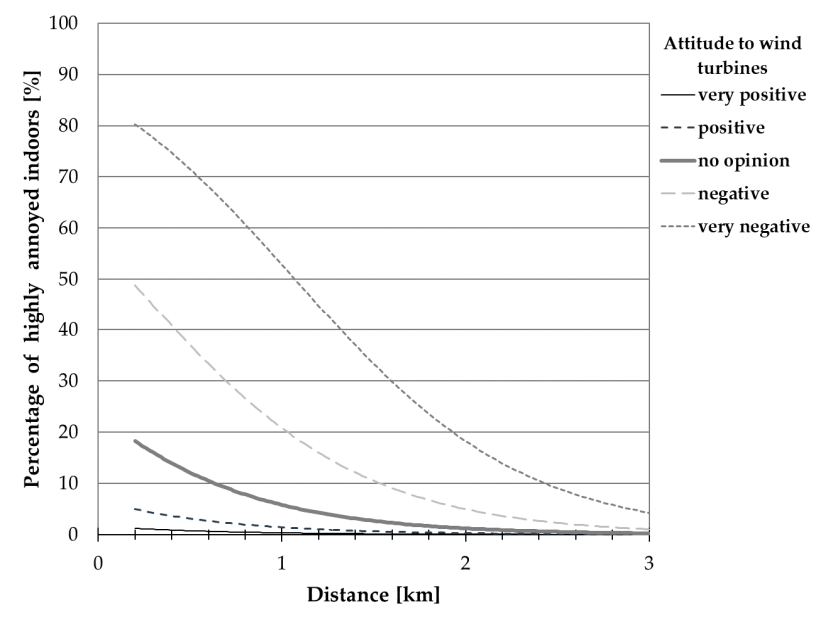

(a)

Figure 10. Cont. 


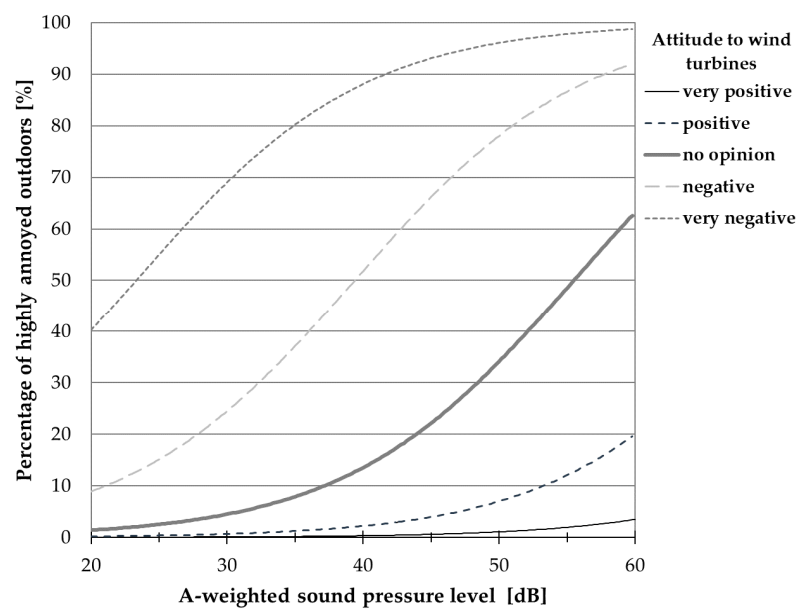

(b)

Figure 10. Percentage of respondents being highly annoyed outdoors by the wind turbine noise as a function of attitude to wind farms and (a) noise level or (b) distance from the nearest wind turbine.

\subsubsection{Factors Affecting Perception of Self-Reported Health}

As mentioned above, the relationships between noise levels (or distance) and self-reported health and well-being were also tested with the binary logistic regression. Since the prevalence of the health symptoms can vary with age and gender, thus these two explanatory variables were taken into consideration. Furthermore, the associations between high annoyance, both outdoors and indoors, were analyzed. In the latter case, apart from age and gender, noise level (or distance) was included into models as a confounder.

As we can see in Table 14, neither the noise level nor the distance from the nearest wind turbine had an impact on various health and well-being aspects. Furthermore, binary logistic regression revealed that almost all variables measuring various health and well-being aspects were positively associated with a high annoyance related to the wind turbine noise both outdoors and indoors. A negative relationship was only observed in case of a self-reported quality of sleep. 
Table 14. Association between various aspects of health and well-being (binary dependent variables) and distance or noise level (independent continuous variable) or annoyance due to the wind turbine noise outdoors (or indoors) (independent binary variable) tested by logistic regression ${ }^{1}$.

\begin{tabular}{|c|c|c|c|c|c|c|}
\hline & \multicolumn{6}{|c|}{ Explanatory Variable } \\
\hline & \multicolumn{6}{|c|}{ Odds Ratio $(95 \%$ CI) } \\
\hline & Distance $^{a}$ & $\begin{array}{l}\text { Highly Annoyed } \\
\text { Outdoors }\end{array}$ & $\begin{array}{l}\text { Highly Annoyed } \\
\text { Indoors b }\end{array}$ & $\begin{array}{l}\text { A-weighted Sound } \\
\text { Pressure Level }^{\text {a }}\end{array}$ & $\begin{array}{l}\text { Highly Annoyed } \\
\text { Outdoors c }\end{array}$ & $\begin{array}{l}\text { Highly Annoyed } \\
\text { Indoors c }\end{array}$ \\
\hline Negative self-assessment of physical health & $0.51(0.16-1.67)$ & $5.48(3.38-8.88)$ & $7.05(4.15-12.01)$ & $1.05(0.98-1.13)$ & $5.46(3.37-8.83)$ & $6.99(4.11-11.87)$ \\
\hline Negative self-assessment of hearing status & $0.63(0.13-3.06)$ & $4.77(2.61-8.73)$ & $5.71(3.03-10.75)$ & $1.06(0.97-1.16)$ & $4.64(2.55-8.47)$ & $5.46(2.92-10.24)$ \\
\hline "Cases" according to the GHQ-12 score & $0.58(0.20-1.64)$ & $5.36(3.34-8.59)$ & $4.68(2.75-7.98)$ & $1.04(0.98-1.11)$ & $5.30(3.31-8.49)$ & $4.62(2.72-7.85)$ \\
\hline Headache & $0.68(0.22-2.11)$ & $3.99(2.50-6.36)$ & $4.07(2.44-6.77)$ & $1.00(0.93-1.07)$ & $4.04(2.53-6.43)$ & $4.16(2.50-6.93)$ \\
\hline Dizziness & $0.27(0.06-1.11)$ & $5.31(3.04-9.29)$ & $5.99(3.38-10.63)$ & $1.05(0.97-1.14)$ & $5.41(3.10-9.45)$ & $6.12(3.45-10.85)$ \\
\hline Heartache & $0.68(0.17-2.83)$ & $4.36(2.48-7.65)$ & $4.47(2.48-8.05)$ & $0.98(0.90-1.07)$ & $4.45(2.54-7.80)$ & $4.64(2.58-8.37)$ \\
\hline Fatigue (undue tiredness) & $0.86(0.30-2.47)$ & $5.36(3.42-8.39)$ & $4.33(2.65-7.09)$ & $0.98(0.92-1.04)$ & $5.46(3.48-8.55)$ & $4.48(2.73-7.34)$ \\
\hline Insomnia & $0.37(0.11-1.26)$ & $8.37(5.02-13.95)$ & $5.90(3.50-9.94)$ & $1.03(0.96-1.11)$ & $8.51(5.11-14.18)$ & $6.05(3.58-10.20)$ \\
\hline Pain and stiffness in back. neck or shoulders & $0.57(0.19-1.75)$ & $1.97(1.25-3.08)$ & $2.07(1.25-3.43)$ & $1.01(0.95-1.08)$ & $1.99(1.27-3.12)$ & $2.11(1.27-3.49)$ \\
\hline $\begin{array}{l}\text { Pulsation in ears } \\
\text { Puts }\end{array}$ & $0.86(0.16-4.73)$ & $6.57(3.30-13.08)$ & $5.42(2.77-10.61)$ & $1.01(0.91-1.11)$ & $6.51(3.28-12.93)$ & $5.40(2.76-10.54)$ \\
\hline Dyspnea & $0.89(0.17-4.81)$ & $3.13(1.66-5.93)$ & $4.78(2.46-9.30)$ & $0.97(0.88-1.07)$ & $3.19(1.69-6.03)$ & $4.95(2.54-9.64)$ \\
\hline Nervousness. tension or stressed & $0.48(0.17-1.35)$ & $5.00(3.23-7.74)$ & $4.20(2.59-6.81)$ & $1.01(0.95-1.07)$ & $5.12(3.31-7.92)$ & $4.35(2.68-7.05)$ \\
\hline Tinnitus & $0.59(0.10-3.49)$ & $6.68(3.28-13.59)$ & $5.94(2.97-11.85)$ & $1.00(0.91-1.11)$ & 6.76 (3.33-13.74) & $6.08(3.05-12.13)$ \\
\hline Respondent woke up well-rested & $0.79(0.32-1.96)$ & $0.42(0.28-0.62)$ & $0.50(0.32-0.80)$ & $1.01(0.95-1.06)$ & $0.42(0.28-0.63)$ & $0.51(0.32-0.81)$ \\
\hline Difficulty in falling asleep & $0.85(0.29-2.48)$ & $5.59(3.55-8.80)$ & $5.26(3.20-8.65)$ & $1.04(0.97-1.11)$ & $5.47(3.48-8.60)$ & $5.13(3.13-8.42)$ \\
\hline Awakened by noise with open window & $1.08(0.39-2.99)$ & $8.38(5.35-13.12)$ & $8.13(4.93-13.39)$ & $1.01(0.95-1.07)$ & $8.20(5.26-12.79)$ & $7.99(4.85-13.14)$ \\
\hline Awakened by noise with closed window & $0.94(0.25-3.49)$ & $9.00(5.18-15.62)$ & $7.76(4.49-13.40)$ & $1.02(0.95-1.11)$ & $8.78(5.07-15.19)$ & $7.55(4.38-13.01)$ \\
\hline Awakened by wind turbines & $0.94(0.25-3.49)$ & $38.03(20.36-71.02)$ & $19.50(10.10-37.64)$ & $1.03(0.96-1.11)$ & $38.17(20.44-71.28)$ & $19.87(10.27-38.42)$ \\
\hline
\end{tabular}

Adjusted for age, gender and the calculated A-weighted sound pressure level. 


\section{Discussion}

One of the most widely investigated responses to environmental noise is an annoyance. Wind turbines are relatively new sources of community noise and their influence on health and well-being of people living nearby has not been completely determined as yet.

For years, most epidemiological evidence concerning the impact of the modern wind turbine noise on people's health and well-being has been coming mainly from three cross-sectional studies carried out in Sweden and the Netherlands between 2000 and 2007 [1-3,5]. Later, cross-sectional studies on human responses to wind turbine noise have been conducted also in other countries, including New Zealand [29], USA [30,31], China [32], Canada [11-13,33] and Poland [15-18]. A questionnaire was applied as the main research tool in almost all of them, excluding the recent Community Noise and Health Study (CNHS) in Canada which assessed responses to the wind turbine noise using both self-reported and objective measures (e.g., measures of blood pressure and heart rate) [13]. It is worth noting that a number of the aforesaid investigations used questionnaires which were designed according to the one previously used in Swedish studies [31,32].

Noise exposures in areas where respondents lived were mainly estimated using the A-weighted sound pressure levels which were calculated from sound power levels of all wind turbines nearby. These calculations were usually supplemented (or verified) by in situ noise measurements [1-3,5,32]. However, Magari et al. [31] based their study on short-term outdoor and indoor sound pressure level measurements at respondents' dwellings. On the other hand, in the Canadian CNHS, both the A- and C-weighted sound pressure levels were calculated for determination of exposure response relationships [11].

In this study, which is a continuation of the previous pilot study, similarly to the aforesaid Scandinavian cross-sectional investigations, the basis of analyses were the results of questionnaire surveys and calculated A-weighted SPLs for areas where respondents lived, which were verified at random by in situ short-term sound pressure level measurements. However, apart from the basic questionnaire (aimed at evaluation of annoyance due to the wind turbine noise and self-assessment of physical health and wellbeing) the respondents were additionally asked to complete the 12-item Goldberg General Health Questionnaire to assess their mental health status. It is worth emphasizing that this questionnaire was used earlier by Bakker et al. [5] to assess the non-specific psychological distress.

In this study, the calculated A-weighted sound pressure level (determined according to the sound propagation model described in ISO 9613-2:1996) ranged from 33 to $50 \mathrm{~dB}$, while the measured A-weighted equivalent-continuous SPL remained within the range from 34 to $50 \mathrm{~dB}$.

The wind turbine noise prevailing at respondents' dwellings included infrasonic components, but at levels lower than the hearing threshold levels (see Figure 1). The G-weighted equivalent-continuous sound pressure level ranged from 53 to $90 \mathrm{~dB}$ within 204-1726 m from the nearest turbine. These results were not surprising since all wind turbines in this study were upwind devices [34].

Earlier, $\mathrm{O}^{\prime} \mathrm{Neal}$ et al. [35] performed noise surveys outside and within nearby residences of wind turbines from two different manufacturers and they also found that the measured (at distances of $305 \mathrm{~m}$ and $457 \mathrm{~m}$ ) sound pressure levels (in 1/3-octave bands) in the infrasonic range were lower than hearing threshold levels. More recently, results similar to our results have been obtained by Song et al. [32] who analyzed noise impacts induced by 2 MW wind turbines in China. Although their sound pressure levels in 1/3-octave bands were higher due to a larger single-machine capacity of wind turbines and a shorter distance between measuring points and the nearest wind turbines, the range of audible frequencies was almost the same, and infrasonic components were also lower than relevant hearing threshold levels [32].

To evaluate the annoyance due to noise from wind turbines, participants of this study completed a questionnaire, which was based on the one previously used in Swedish and Dutch studies [1-3]. Furthermore, to reduce a self-reporting survey bias, like that inherent to the aforesaid questionnaire, it included also questions about several potential environmental stressors and did not allow 
respondents to realize that the focus of the study was on the wind turbine noise. It is worth noting that there was a high correspondence between the responses to the general questions of noise from the wind turbine at the beginning of the Swedish questionnaire and the more specific questions later (expressed by Cronbach's $\alpha$ coefficient equal to 0.885) [1]. Statistical analysis of data from the pilot study also confirmed a high internal consistency of different questions evaluating the response to wind turbines (alpha $=0.93$ ) [17].

Generally, earlier cross-sectional studies showed that the proportion of people being annoyed by the wind turbine noise increased along with increasing noise levels [1-3,5] or reduced proximity to wind turbines [29]. It has also been found that subjects were more likely to be annoyed when calculated A-weighted sound pressure levels exceeded 35-40 dB [2,3]. Furthermore, the wind turbine noise was found to be more annoying than transportation noise or industrial noise at comparable levels, possibly due to specific sound properties such as a "swishing" quality, temporal variability, and lack of the night time abatement [3]. Some personal factors (such as having turbines visible from the dwelling, negative opinion about wind turbines in general and/or their visual impact on landscape and self-reported sensitivity to noise) appeared to increase the odds of being annoyed by the wind turbine noise [1,2].

On the other hand, especially in the Dutch studies, the risk of annoyance was considerably lower in the subjects obtaining economic benefits from wind turbines [3]. Moreover, according to the aforesaid studies the perception and annoyance were associated with the terrain and urbanization, i.e., a rural area increased the risk of perception and annoyance in comparison with a suburban area, in a rural setting a diversified (hilly or rocky) terrain increased the risk compared with a flat terrain [2]. In turn, according to more recently published results of the Canadian study (CNHS), variables associated with the wind turbine noise annoyance comprised, but were not limited to, other wind turbine-related annoyances (e.g., shadow flickers), personal benefits, noise sensitivity, physical safety concerns, property ownership and province of Canada [12].

Our pilot study included only respondents living in the countryside or in small villages located in the rather flat and mainly agricultural terrain with low traffic intensity. However, the final study population included inhabitants of rural and suburban areas (near small towns) with diversified terrain shape and road-traffic intensity. Thus, we could analyze the impact of terrain shape and road-traffic intensity on annoyance related to the wind turbine noise.

To explore the prevalence of annoyance related to the wind turbine noise, when relevant answers to questionnaire on 5- or 6-point verbal rating scales were dichotomized. In particular, likewise in case of transportation and industrial noise, where the cutoff at 50 and 72 on a $0-100$ rating scale was related to terms "annoyed" and "highly annoyed", respectively [36], in this study annoyance ratings $\geq 2$ and $\geq 3$ (on 0-4 scale) were categorized as "annoying" and "highly annoying", respectively.

It appeared that the wind turbine noise at calculated A-weighted sound pressure levels of 34-50 dB was perceived outdoors as annoying (i.e., as "rather annoying", "annoying" or "extremely annoying") or highly annoying (i.e., as "annoying" or "extremely annoying") by 46.4 and $28.0 \%$ of respondents, respectively. On the other hand, $33.7 \%$ and $18.4 \%$ of them said that they were annoyed or highly annoyed indoors, respectively.

Recently, based on the available data from Swedish and Dutch cross-sectional studies [1-3], the exposure-response relationships between the exposure metric $\mathrm{L}_{\mathrm{den}}$ (annual day-evening-night noise level according to 2002/49/EC [22]) and self-reported annoyance indoors as well as outdoors of the dwellings due to the wind turbine noise were determined using the method previously applied to derive the exposure-response relationships for transportation and industrial noise [37]. To obtain the exposure metrics $\mathrm{L}_{\mathrm{den}}$, a correction of $+4.7 \mathrm{~dB}$, calculated by van den Berg [23], was added by Janssen et al. [37] to the predicted A-weighted SPLs. Finally, four exposure-response relationships showing the percentages of annoyed and highly-annoyed residents by the wind turbine noise at given $L_{d e n}$, were determined. Generally, in comparison to other sources of environmental noise, annoyance due to the wind turbine noise was found at relatively low noise exposure levels. 
To compare the percentages of subjects being annoyed (or highly annoyed) by the wind turbine noise observed in this study with the predictions of the aforesaid exposure-response relationships, the calculated A-weighted sound pressure levels were also corrected to obtain the exposure metrics $\mathrm{L}_{\mathrm{den}}$ (Table 4). Furthermore, the study population was divided into 10 equinumerous categories due to the $\mathrm{L}_{\mathrm{den}}$ level and proportions of subjects being annoyed and highly annoyed were determined.

The percentages - observed in this study — of respondents being highly annoyed, both outdoors and indoors, by wind turbines noise at given $\mathrm{L}_{\mathrm{den}}$ levels fitted quite well the proposed exposure-response curves (Figures $11 \mathrm{~b}$ and $12 \mathrm{~b}$ ). However, when analyzing the percentage of subjects being annoyed (outdoors or indoors), a good agreement with the aforesaid predictions was noted for the $\mathrm{L}_{\mathrm{den}}$ levels above $45 \mathrm{~dB}$ (Figures 11a and 12a).

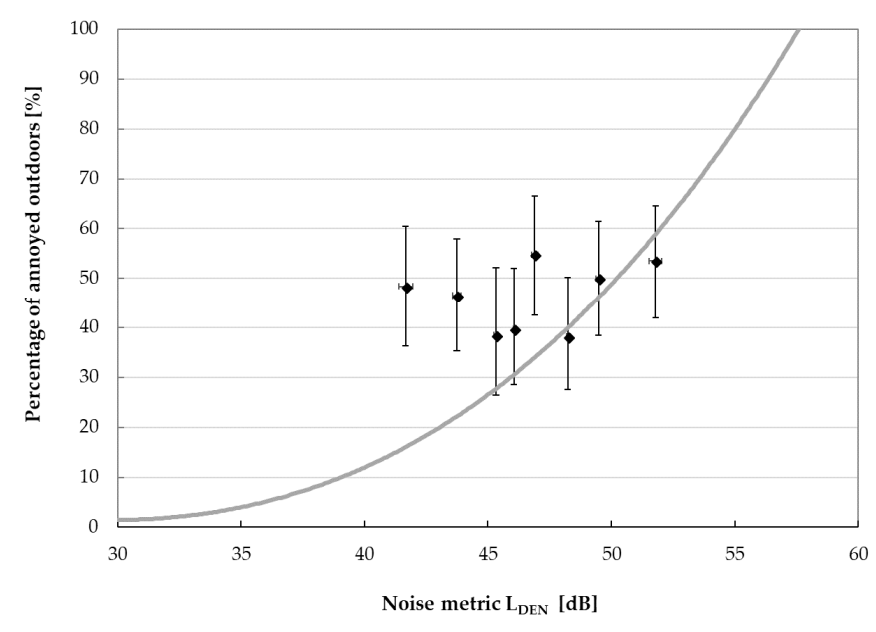

(a)

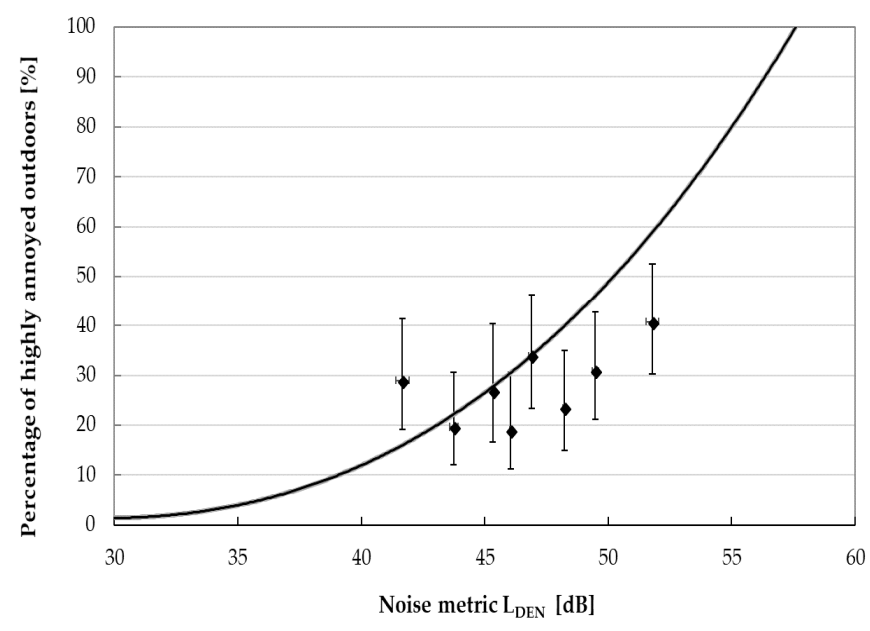

(b)

Figure 11. Comparison of observed proportions (with 95\% confidence levels) of respondents being (a) annoyed and (b) highly annoyed outdoors by the wind turbine noise to exposure-response relationships for wind turbine annoyance outdoors proposed by Janssen et al. Dots with whiskers represent survey data with $95 \%$ confidence intervals. 


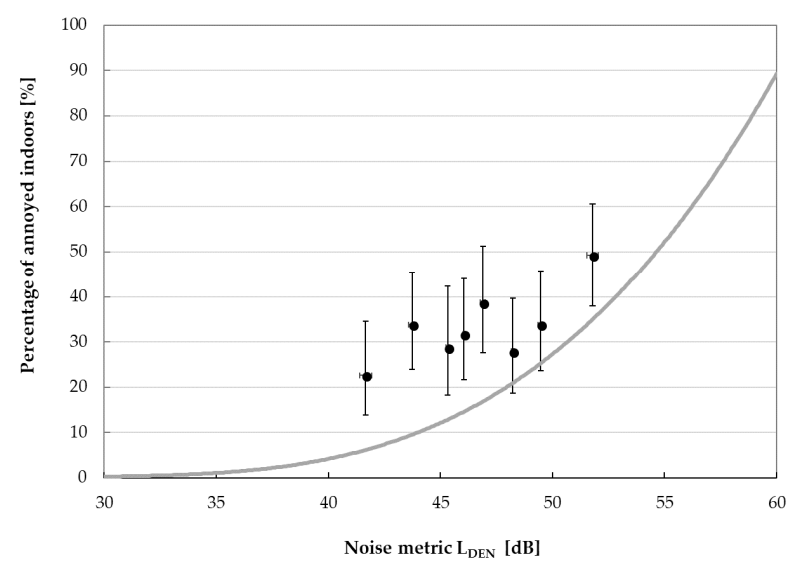

(a)

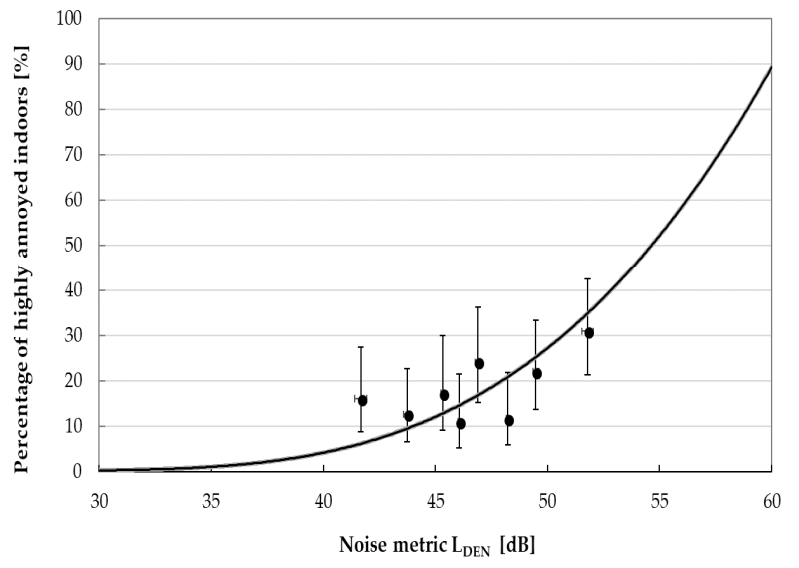

(b)

Figure 12. Comparison of observed proportions (with 95\% confidence levels) of respondents being (a) annoyed and (b) highly annoyed indoors by the wind turbine noise to exposure-response relationships for wind turbine annoyance outdoors proposed by Janssen et al. Dots with whiskers represent survey data with $95 \%$ confidence intervals.

As mentioned above, a general conclusion from other previous studies was that annoyance increased with increasing wind turbine noise levels [1-3,5,11] or reduced proximity to wind turbines [29]. For example, in a recent Canadian study the increase in high annoyance was clearly evident when moving from noise category $30-35 \mathrm{~dB}$ to $35-40 \mathrm{~dB}$, where the prevalence increased from $1 \%$ to $10 \%$, and this continued to increase to $13.7 \%$ at $40-46 \mathrm{~dB}$ [11].

In this study, the proportion of subjects being annoyed (or highly annoyed), both outdoors and indoors, in majority cases decreased significantly with a greater distance from the nearest wind turbine (Figure 4). However, contrary to the majority of other investigations, when analyzing annoyance (both outdoors and indoors) in various noise categories, no significant differences were noted. Observed was only a tendency to an increasing percentage of subjects being highly annoyed outdoors or annoyed (and highly annoyed) indoors along with increasing noise levels (Figure 4). It is worth noting that generally the relationships between the distance (or noise) and "high annoyance" were more pronounced than in the case of "annoyance".

Nevertheless, the results of our study are partly in line with the observations from earlier cross-sectional investigations, since the results of logistic regression have shown that odds ratio of being highly annoyed indoors increased approximately 1.1 times per each $1 \mathrm{~dB}$ increase of sound 
pressure level and noise level itself explains approximately $2 \%$ of variance in high annoyance indoors (Table 11).

Such relationships were not found when analyzing the high annoyance outdoors. However, about $1 \%$ of variance in high annoyance can be explained by the distance itself, and odds ratio that respondents would be highly annoyed outdoors decreased approximately three times if the distance increased by $1 \mathrm{~km}(\mathrm{OR}=0.33 ; 95 \%$ CI: 0.12-0.92) (Table 10).

In this study over half of the subjects were classified as sensitive to noise $(68.3 \%)$ and landscape littering (63.6\%). Of the respondents, $40.3 \%$ and $32.3 \%$ declared negative ("very negative" or "negative") attitude towards wind turbines in general and their visual impact in particular, respectively. The majority of subjective (individual) factors (i.e., sensitivity to various environmental nuisances, attitude to wind turbines, physical and mental health status) were correlated to each other (Table 3). In particular, there was a relatively high positive correlation between the attitude toward wind turbines in general and the attitude to their visual impact in particular as well as between the respondents' sensitivity to noise and sensitivity to landscape littering. Furthermore, a percentage of subjects negatively assessing wind turbines in general and their impact on landscape in particular, decreased significantly when moving from noise category $>45 \mathrm{~dB}$ (or $40-45 \mathrm{~dB}$ ) to $<35 \mathrm{~dB}$. On the other hand, the greater distance from the nearest wind turbine, the smaller the percentage of subjects with negative opinion towards wind turbines (Table 2).

To analyze the influence of subjective (or individual) and objective (situational) factors (including noise level and distance) on annoyance rating binary logistic regression was applied. However, due to high positive correlations between the aforesaid subjective variables in the study subjects, only some of them, namely the general attitude towards wind turbines and sensitivity to noise and landscape littering were taken into consideration. Other analyzed factors, having a possible impact on annoyance perception, were age, gender, education, terrain shape, road traffic intensity, time since the start-up of the wind farm, power and height of the nearest wind turbine, economic benefits from the wind farm and having wind turbines visible from dwelling.

It has been shown that the probability of being highly annoyed outdoors was significantly associated with the sound pressure level (or distance), attitude towards wind turbines, sensitivity to noise as well as terrain shape. On the other hand, the annoyance perception indoors was correlated with the noise level (or distance), age, attitude towards wind turbines, sensitivity to noise and traffic intensity. No significant relationships were observed in case of the remaining factors (Tables 8 and 9).

Almost all study subjects could see one or more wind turbines from their dwelling, while only a few $(6.1 \%)$ of them had profits from the wind turbines. Thus, it is not surprising that no significant associations were noted between these factors and noise annoyance.

When exploring the factors affecting a high annoyance outdoors using binary logistic regression, the highest value of the explained variance (approximately 66\%) was obtained for the models containing a distance or noise level (only in case of high annoyance) and general attitude to wind turbines, noise sensitivity and terrain shape. However, a similar percentage of explained variance (approximately 61\%) was obtained when only the noise level (or distance) and the general attitude to wind turbines were included into the model.

On the other hand, when testing high annoyance indoors, the greatest values of explained variance (approximately 48\%) were obtained for the model containing the noise level and general attitude to wind turbines, noise sensitivity and road-traffic intensity. Moreover, likewise in case of a probability of being annoyed outdoors, the percentage of explained variance decreased slightly (to approximately $45 \%$ ) if only the noise level (or distance) and general attitude to wind turbines were taken into consideration.

Generally, the odds ratio of being highly annoyed by the wind turbine noise (both outdoors and indoors) increased with increasing noise level, higher sensitivity to noise and more negative attitude towards wind turbines, while it decreased with an increasing distance from the nearest wind turbine. Similarly, hilly or mountainous (vs. flat) terrain and no or low-intensity (vs. increased intensity) 
road-traffic increased the risk of being annoyed outdoors and indoors, respectively. Thus, the findings obtained in this study confirmed the conclusions from the earlier Dutch studies, that annoyance perception was associated with terrain and urbanization, i.e., a rural area increased the risk of perception and annoyance in comparison with a suburban area, in a rural setting a diversified (hilly or rocky) terrain increased the risk compared with a flat terrain [3].

It is worth emphasizing that inclusion of the road-traffic intensity into the model is equivalent to taking into account the prevalence of masking noise, namely road-traffic noise. Furthermore, our findings are also in line with Scandinavian observations that people living with other background noises are less affected by the wind turbine noise than those from the quiet areas [5]. However, it has been shown that the road traffic noise can provide a significant masking of the wind farm noise, but only at intermediate levels of the wind turbine sound (35-40 dBA), not at higher or lower levels [38].

Over one-fifth of our study subjects assessed their physical health negatively, while nearly every fifth or fourth subject frequently reported stress symptoms such as headache $(21.3 \%)$, undue tiredness $(27.1 \%)$, feeling nervous, tense or stressed $(28.0 \%)$. Furthermore, of total respondents, $25.1 \%$ had often difficulty falling asleep, while $19.3 \%$ of them complained of insomnia. Nearly half $(45.8 \%)$ of them often woke up not well-rested. Regarding sleep disturbances, $27.3 \%$ of the subjects stated they were disturbed in their sleep by noise from various sources (including the road traffic noise and wind turbine noise) when sleeping with an open window, while $15.1 \%$ of them were disturbed when sleeping with a closed window. Moreover, about one-third (33.7\%) of the study subjects stated that they were wakened by the wind turbines.

Respondents examined using the GHQ-12 obtained a mean score at the level of $12.5 \pm 6.1$ which was similar to the normative result for the reference Polish population (11.17 \pm 5.11$)$. Furthermore, the prevalence of "cases" (35\%) in the study population was comparable to that observed in the Polish healthy working population (27\%) [18].

As to various health and well-being aspects, there were no significant differences between noise or distance categories (Figure 6). However, people being annoyed (or highly) annoyed by the wind turbine noise more frequently than those not annoyed assessed their mental health negatively, reported stress symptoms, and stated that they were disturbed in their sleep by the noise from wind turbines. Furthermore, a greater percentage of the so-called "cases" according to the GHQ-12 score were recognized among annoyed (or highly annoyed) subjects. Those findings were supported by the binary logistic regression which confirmed that almost all variables measuring various health and well-being aspects were positively associated with a high annoyance related to the wind turbine noise both outdoors and indoors, while there were no significant associations with the noise level or the distance from the nearest wind turbine.

The above mentioned findings confirmed some conclusions from earlier Scandinavian cross-sectional studies, since analysis of the combined data from these investigations showed that the subjects who were annoyed by the wind turbine noise were more likely to report sleep disturbances, feeling tense, stressed and irritable [38]. Our findings are also in agreement with the results from CNHS which did not support an association between the exposure to the wind turbine noise (up to $46 \mathrm{dBA}$ ) and self-reported health effects (e.g., migraines, tinnitus, dizziness), sleep disturbances and sleep disorders, as well as elevated self-reported and objectively defined measures of stress $[12,13]$. On the other hand, our results are contrary to the findings obtained by Nissenbaum et al. [30] indicating that the subjects living within $1.4 \mathrm{~km}$ of an industrial wind turbine could not sleep well, they were more sleepy during the day, and had worse SF36 Mental Components Scores, as compared to those living further than $1.4 \mathrm{~km}$.

Results of binary logistic regression were the basis for determination of exposure-response relationships expressed as the probability (percentage) of being highly annoyed in the function of the calculated A-weighted sound pressure level (or distance) and other explanatory variables, including the general attitude to wind turbines, sensitivity to noise, and road-traffic intensity or the 
terrain shape. According to the aforesaid curves, namely those relating annoyance to sound pressure level (or distance) and attitude towards turbines, in areas where the A-weighted sound pressure level exceeds $40 \mathrm{~dB}$, above $2 \%$ and $52 \%$ of the people with positive and negative attitudes to the wind farm, respectively, might be highly annoyed outdoors (Figure $9 \mathrm{~b}$ ). At such noise exposures, above $27 \%$ of the subjects with negative opinions about wind farms might assess the wind turbine noise as annoying indoors (Figure 10b). On the other hand, at the distance of $1000 \mathrm{~m}$ the wind turbine noise might be perceived as highly annoying outdoors by approximately $2 \%$ and $43 \%$ of the people with a positive and negative attitude towards wind farms, respectively (Figure $9 a$ ). At the same distance, up to $21 \%$ of the subjects (with negative attitude to wind farms) might be highly annoyed by the wind turbine noise indoors (Figure 10a).

According to the obtained exposure-response curves we can estimate that even among the people with very negative attitudes to the wind turbines, at relatively long $(>2.1 \mathrm{~km})$ distances from the wind turbines the percentage of those evaluating the noise as very tiresome (both outdoors and indoors) will not exceed $10 \%$.

The relationships between the self-reported annoyance and distance (and other factors) seem to be useful in selecting setback distances to reduce or avoid potential noise complaints from, or potential effects to, people living close to wind farms. This is important, since several unreliabilities related to the calculations might result in over- or underestimation of noise levels experienced in everyday life in the vicinity of wind farms.

It is worth emphasizing that minimum setback distances have been established world-wide to reduce or avoid potential noise complaints from, or potential effects to, the people living close to wind turbines. For example, in Ontario a minimum setback distance of $550 \mathrm{~m}$ must exist between the center of the base of the wind turbine and the nearest noise receptor (e.g., a building or campground). That minimum setback distance was developed through noise modeling under worst-case conditions to give a conservative estimate of the distance at which the noise attains the A-weighted sound level of $40 \mathrm{~dB}$ [4], the noise level that corresponds to the WHO night-noise guideline, a health-based limit [39]. On the other hand, the Queensland guidelines specify a minimum setback distance of 1.5 $\mathrm{km}$. According to Davy et al. [40], this came from a National Health and Medical Research Council information paper which states: "Although individuals may perceive aspects of wind farm noise at greater distances, it is unlikely that the wind farm noise will be considered disturbing at distances of $>1500 \mathrm{~m}^{\prime \prime}$.

According to exposure-relationship curves which were determined in this study, at such a distance less than $10 \%$ of people with negative attitude towards wind turbines might be highly annoyed indoors. However, to keep the percentage of people highly annoyed when outdoors in the value of less than $10 \%$ the distance should be greater than $2.1 \mathrm{~km}$.

Taking into account the fact that evaluation of the wind turbines noise annoyance depends on many interrelated subjective and objective factors and that the interrelations between those factors are not known sufficiently as yet, it would be advisable to create the noise annoyance model involving only objective (or situational) factors such as e.g., the distance of dwellings from the nearest wind turbine.

\section{Conclusions}

It has been shown that the wind turbine noise at the calculated A-weighted sound pressure level of 33-50 dB was perceived as annoying or highly annoying by $46 \%$ and $28 \%$ of respondents living within $204-1726 \mathrm{~m}$ from the nearest wind turbine, respectively. On the other hand, $34 \%$ and $18 \%$ of them said that they were annoyed or highly annoyed indoors, respectively.

The perception of annoyance and high annoyance was associated with the A-weighted sound pressure level or the distance from the nearest wind turbine, general attitude to wind farms, noise sensitivity and terrain shape (annoyance outdoors) or road-traffic intensity (annoyance indoors). About $48-66 \%$ of variance in annoyance might be explained by the aforesaid factors. However, 
the relationships between the distance (or sound pressure level) and "high annoyance" were more pronounced than those with "annoyance".

The odds ratio of being highly annoyed by the wind turbine noise (both outdoors and indoors) increased with an increasing noise level, higher sensitivity to noise and more negative attitude towards wind turbines, while it decreased with an increasing distance from the nearest wind turbine. Similarly, hilly or mountainous (vs. flat) terrain and no or low-intensity (vs. increased intensity) road-traffic increased the risk of being annoyed outdoors and indoors, respectively.

The percentage of respondents being annoyed by the wind turbine noise strongly depended on their attitude to wind turbines. It was estimated that in areas where the A-weighted sound pressure level exceeds $40 \mathrm{~dB}$, above $52 \%$ of people with negative attitude to wind farms might be highly annoyed outdoors, as opposed to $2 \%$ of those with a positive attitude. On the other hand, at a distance of $1000 \mathrm{~m}$ the wind turbine noise might be perceived as highly annoying outdoors by approximately $43 \%$ and $2 \%$ of people with negative and positive attitude to wind turbines, respectively.

There was no significant association between the noise level (or distance) and various health and well-being aspects. However, almost all variables measuring health and well-being aspects, including stress symptoms and self-reported sleep disturbances, were positively associated with high annoyance related to the wind turbine noise both outdoors and indoors.

The relationships between annoyance and distance (and other factors) seem to be useful in selecting setback distances to reduce or avoid potential noise complaints from, or potential effects to, people living close to wind farms. This is important, since several unreliabilities related to the calculations might result in over- or underestimation of noise levels experienced in everyday life in the vicinity of wind farms.

Nevertheless, further studies are needed, in particular those using both self-reported and objective measures, before firm conclusions can be drawn on the impact of the wind turbine noise on health and well-being.

Author Contributions: Conceptualization, M.P.-Ł.; Methodology, M.P.-Ł.; Software, K.Z. and A.D.; Validation, M.P.-Ł., A.D., M.W. and K.Z.; Formal Analysis, M.P.-Ł.; Investigation, M.P.-Ł., A.D., M.Z.-D. and K.Z; Resources, M.P.-Ł., A.D., M.Z.-D. and K.Z; Data Curation, M.P.-Ł., A.D., M.Z.-D. and K.Z; Writing-Original Draft Preparation, M.P.-Ł. and K.Z; Writing-Review \& Editing, M.P.-Ł., A.D., M.Z.-D. and K.Z; Visualization, M.P.-Ł., A.D., M.Z.-D. and K.Z; Supervision, M.P.-Ł.; Project Administration, M.P.-Ł.; Funding Acquisition, M.P.-Ł.

Funding: This study was supported by the Ministry of Science and Higher Education of Poland (Grants IMP 18.5/2011-2012 and IMP 17.1/2013-2014).

Acknowledgments: The authors would like to thank the participants for their response, and anonymous reviewers and journal editors for their valuable comments.

Conflicts of Interest: The authors declare no conflict of interest.

\section{References}

1. Pedersen, E.; Persson Waye, K. Perception and annoyance due to wind turbine noise-A dose-response relationship. J. Acoust. Soc. Am. 2004, 116, 3460-3470. [CrossRef] [PubMed]

2. Pedersen, E.; Persson Waye, K. Wind turbine noise, annoyance and self-reported health and well-being in different living environments. Occup. Environ. Med. 2007, 64, 480-486. [CrossRef] [PubMed]

3. Pedersen, E.; Van den Berg, F.; Bakker, R.; Bouma, J. Response to noise from modern wind farms in The Netherlands. J. Acoust. Soc. Am. 2009, 126, 634-643. [CrossRef] [PubMed]

4. Knopper, L.D.; Ollson, C.A. Health effects and wind turbines: A review of the literature. Environ. Health 2010, 78, 1-10. [CrossRef] [PubMed]

5. Bakker, R.H.; Pedersen, E.; van den Berg, G.P.; Stewart, R.E.; Lok, W.; Bouma, J. Impact of wind turbine sound on annoyance, self-reported sleep disturbances and psychological distress. Sci. Total Environ. 2012, 425, 42-45. [CrossRef] [PubMed]

6. Pedersen, E. City dweller responses to multiple stressors intruding into their homes: Noise, light, odour, and vibration. Int. J. Environ. Res. Public Health 2015, 12, 3246-3263. [CrossRef] [PubMed] 
7. Persson Waye, K.; Öhtrsöm, E. Psycho-acoustic characters of relevance for annoyance of wind turbine noise. J. Sound Vib. 2002, 250, 65-73. [CrossRef]

8. Lee, S.; Kim, K.; Choi, W.; Lee, S. Annoyance caused by amplitude modulation of wind turbine noise. Noise Control Eng. J. 2011, 59, 38-46. [CrossRef]

9. Pedersen, E.; Larsman, P. The impact of visual factor on noise annoyance among people living in the vicinity of wind turbines. J. Environ. Psychol. 2008, 28, 379-389. [CrossRef]

10. Maffei, L.; Iachini, T.; Masullo, M.; Aletta, F.; Sorrentino, F.; Senese, V.P.; Ruotolo, F. The effects of vision-related aspects on noise perception of wind turbines in quiet areas. Int. J. Environ. Res. Public Health 2013, 10, 1681-1697. [CrossRef] [PubMed]

11. Michaud, D.S.; Feder, K.; Keith, S.E.; Voicescu, S.A.; Marro, L.; Than, J.; Guay, M.; Denning, A.; McGuire, D.; Bower, T.; et al. Exposure to wind turbine noise: Perceptual responses and reported health effects. J. Acoust. Soc. Am. 2016, 139, 1443-1454. [CrossRef] [PubMed]

12. Michaud, D.S.; Keith, S.E.; Feder, K.; Voicescu, S.A.; Marro, L.; Than, J.; Guay, M.; Denning, A.; Lavigne, E.; Whelan, C.; et al. Personal and situational variables associated with wind turbine noise annoyance. J. Acoust. Soc. Am. 2016, 139, 1455-1466. [CrossRef] [PubMed]

13. Michaud, D.S.; Feder, K.; Keith, S.E.; Voicescu, S.A.; Marro, L.; Than, J.; Guay, M.; Denning, A.; Bower, T.; Villeneuve, P.J.; et al. Self-reported and measured stress related responses associated with exposure to wind turbine noise. J. Acoust. Soc. Am. 2016, 139, 1467-1479. [CrossRef] [PubMed]

14. Michaud, D.S.; Feder, K.; Voicescu, S.A.; Marro, L.; Than, J.; Guay, M.; Lavigne, E.; Denning, A.; Murray, B.J.; Weiss, S.K.; et al. Clarifications on the design and interpretation of conclusions from health Canada's study on wind turbine noise and health. Acoust. Aust. 2018, 46, 99-110. [CrossRef]

15. Mroczek, B.; Kurpas, D.; Karakiewicz, B. Influence of distances between places of residence and wind farms on the quality of life in nearby areas. Ann. Agric. Environ. Med. 2012, 19, 692-696. [PubMed]

16. Mroczek, B. Quality of Life of People Living in Wind Farm Areas; PPH Zapol: Szczecin, Poland, 2013. (In Polish)

17. Pawlaczyk-Łuszczyńska, M.; Dudarewicz, A.; Zaborowski, K.; Zamojska-Daniszewska, M.; Waszkowska, M. Evaluation of annoyance from the wind turbine noise: A pilot study. Int. J. Occup. Med. Environ. Health 2014, 27, 364-388. [CrossRef] [PubMed]

18. Makowska, Z.; Merecz, D. Polish adaptation of David Goldberg's General Health Questinnaires: GHQ-12 and GHQ-28. In Assessment of Mental Health Status Using David Goldberg's Questionnaires. Guide for Users of GHQ-12 and GHQ-28; Dudek, B., Ed.; Nofer Institute of Occupational Medicine: Łódź, Poland, 2001. (In Polish)

19. Makowska, Z.; Merecz, D.; Mościcka, A.; Kolasa, W. The validity of general health questionnaires, GHQ-12 and GHQ-28, in mental health studies of working people. Int. J. Occup. Med. Environ. Health 2002, 15, 353-362. [PubMed]

20. International Organization for Standardization. Attenuation of Sound during Propagation Outdoors. Part 2: General Method of Calculation; ISO 9613-2; International Organization for Standardization: Geneva, Switzerland, 1996.

21. Geoportal.gov.pl. Head Office of Geodesy and Cartography; Geoportal.gov.pl: Warszawa, Poland, 2014.

22. Directive, E. U. Directive 2002/49/EC of the European Parliament and of the Council of 25 June 2002 relating to the assessment and management of environmental noise. Off. J. Eur. Commun. 2002, L189, 12-25.

23. Van den Berg, F. Criteria for wind farm noise: Lmax and Lden. In Proceedings of the 7th European Conference on Noise Control, Euronoise (Acoustics '08), Paris, France, 29 June-4 July 2008.

24. Regulation of the Minister of the Environment of October 30, 2014 on The Requirements for the Measurement of Emission Volumes and Measurements of the Amount of Water Consumed. Available online: http:// prawo.sejm.gov.pl/isap.nsf/download.xsp/WDU20140001542/O/D20141542.pdf (accessed on 23 July 2018). (In Polish)

25. Nagelkerke, N.J.D. A note on the general definition of the coefficient of determination. Biometrika 1991, 78, 691-692. [CrossRef]

26. Leventhall, G.; Pelmear, P.; Benton, S. A Review of Published Research on Low Frequency Noise and Its Effects; Department for Environment, Food Rural Affairs: London, UK, 2003.

27. ISO. International Standard ISO 226: Acoustics-Normal Equal-Loudness-Level Contours; ISO: Geneva, Switzerland, 2003. 
28. Pedersen, E. Health aspects associated with wind turbine noise-Results from three field studies. Noise Control Eng. J. 2011, 59, 47-53. [CrossRef]

29. Shepherd, D.; McBride, D.; Welch, D.; Dirks, K.N.; Hill, E.M. Evaluating the impact of wind turbine noise on health-related quality of life. Noise Health 2011, 13, 333-339. [CrossRef] [PubMed]

30. Nissenbaum, M.A.; Aramini, J.J.; Hanning, C.D. Effects of industrial wind turbine noise on sleep and health. Noise Health 2012, 14, 237-243. [CrossRef] [PubMed]

31. Magari, S.R.; Smith, C.E.; Schiff, M.; Rohr, A.C. Evaluation of community response to wind turbine-related noise in western New York state. Noise Health 2014, 16, 228-239. [CrossRef] [PubMed]

32. Song, K.; Di, G.; Xu, Y.; Chen, X. Community survey on noise impacts induced by $2 \mathrm{MW}$ wind turbines in China. J. Low Freq. Noise Vib. Act. Control 2016, 35, 279-290. [CrossRef]

33. Krogh, C.M.E.; Gillis, L.; Kouwen, N.; Aramini, J. WindVOiCe, a self-reporting survey: adverse health effects, industrial wind turbines, and the need for vigilance monitoring. Bul. Sci. Technol. Soc. 2011, 31. [CrossRef]

34. Leventhall, G. Infrasound from wind turbines-Facts, fiction or deception. Can. Acoust. 2006, 34, $29-34$.

35. O'Neal, R.D.; Hellweg, R.D., Jr.; Lampeter, R.M. Low frequency noise and infrasound from wind turbines. Noise Control Eng. J. 2011, 59, 135-157. [CrossRef]

36. Schultz, T.J. Synthesis of social surveys on noise annoyance. J. Acoust. Soc. Am. 1978, 64, 73-85. [CrossRef]

37. Janssen, S.A.; Vos, H.; Eisses, A.R.; Pedersen, E. A comparison between exposure-response relationships for wind turbine annoyance and annoyance due to other noise sources. J. Acoust. Soc. Am. 2011, 130, 3746-3753. [CrossRef] [PubMed]

38. Pedersen, E.; Van den Berg, F.; Bakker, R.; Bouma, J. Can road traffic mask sound from wind turbines? Response to wind turbine sound at different levels of road traffic sound. Energy Policy 2010, 38, 2520-2527. [CrossRef]

39. Night Noise Guidelines for Europe World Health Organization Regional Office for Europe, Copenhagen 2009. Available online: http:/ / www.euro.who.int/_data/assets/pdf_file/0017/43316/E92845.pdf (accessed on 13 July 2018).

40. Davya, J.L.; Burgemeisterb, K.; Hillmanc, D. Wind turbine sound limits: Current status and recommendations based on mitigating noise annoyance. Appl. Acoust. 2018, 140, 288-295. [CrossRef]

(C) 2018 by the authors. Licensee MDPI, Basel, Switzerland. This article is an open access article distributed under the terms and conditions of the Creative Commons Attribution (CC BY) license (http:/ / creativecommons.org/licenses/by/4.0/). 